\title{
Propeller Excitation of Longitudinal Vibration Characteristics of Marine Propulsion Shafting System
}

\author{
Ganbo Zhang, Yao Zhao, Tianyun Li, and Xiang Zhu \\ School of Naval Architecture and Ocean Engineering, Huazhong University of Science and Technology, \\ Wuhan 430074, China \\ Correspondence should be addressed to Ganbo Zhang; hustzgb@126.com
}

Received 29 May 2013; Accepted 27 July 2013; Published 31 March 2014

Academic Editor: Valder Steffen

Copyright (c) 2014 Ganbo Zhang et al. This is an open access article distributed under the Creative Commons Attribution License, which permits unrestricted use, distribution, and reproduction in any medium, provided the original work is properly cited.

\begin{abstract}
The submarine experiences longitudinal vibration in the propulsion shafting system throughout most of run. A transfer matrix model of the propulsion shafting system, in which the dynamic characteristics of oil film within thrust bearing are considered, is established to describe the dynamic behavior. Using hydrodynamic lubrication theory and small perturbation method, the axial stiffness and damping of oil film are deduced in great detail, followed by numerical estimation of the foundation stiffness with finite element method. Based upon these values of dynamic parameters, the Campbell diagram describing natural frequencies in terms of shafting rotating speeds is available, and the effect on the 1st natural frequency of considerable variations in thrust bearing stiffness is next investigated. The results indicate that the amplitude of variation of the 1st natural frequency in range of low rotating speeds is great. To reduce off-resonance response without drastic changes in propulsion shafting system architecture, the measure of moving thrust bearing backward is examined. The longitudinal vibration transmission through propulsion shafting system results in subsequent axial excitation of hull; the thrust load acting on hull is particularly concerned. It is observed that the measures of structural modification are of little benefit to minimize thrust load transmitted to hull.
\end{abstract}

\section{Introduction}

For marine vessels, propulsion shafting is an essential changer of engine torque and propeller thrust. Modern submarine is mostly equipped with the electric propulsion plant, realizing the mechanical separation between diesel generator and propulsion motor. Thereby, the unsteady propeller thrust constitutes the sole excitation source of longitudinal vibration in propulsion shafting system. It should be mentioned that this type of vibration is an inherent vibration attached to propeller propulsion technology. Unless the new thruster is adopted, this type of vibration cannot be eliminated thoroughly. The submarine propulsion shafting system consists of propeller, stern shaft, intermediate shaft, journal bearing, thrust bearing, and flexible coupling, as shown in Figure 1.

Due to existence of nonuniform flow field near the propeller caused by asymmetry in hull and protrusions of control surfaces, the axial excitation which occurs at the propeller is the result of variations in thrust when the propeller blades rotate through the nonuniform wake. The frequency of this disturbance is well known as blade passing frequency, which is equal to the shafting rotating speed multiplied by the number of blades [1]. The longitudinal vibration of propulsion shafting is an evidence of fluctuations in propeller thrust. This type of vibration is likely to cause harm to propulsion system, including increased wear of thrust bearing and flexible coupling as a result of increased relative motion between fixed and rotating parts. These equipment failures firstly occurred in surface warships and were of particular concern to the navy, and then theoretical and experimental researches on longitudinal vibration of geared turbine shafting were subsequently initiated [2].

The transmission path of propeller thrust in propulsion shafting system can be described as follows: propeller 


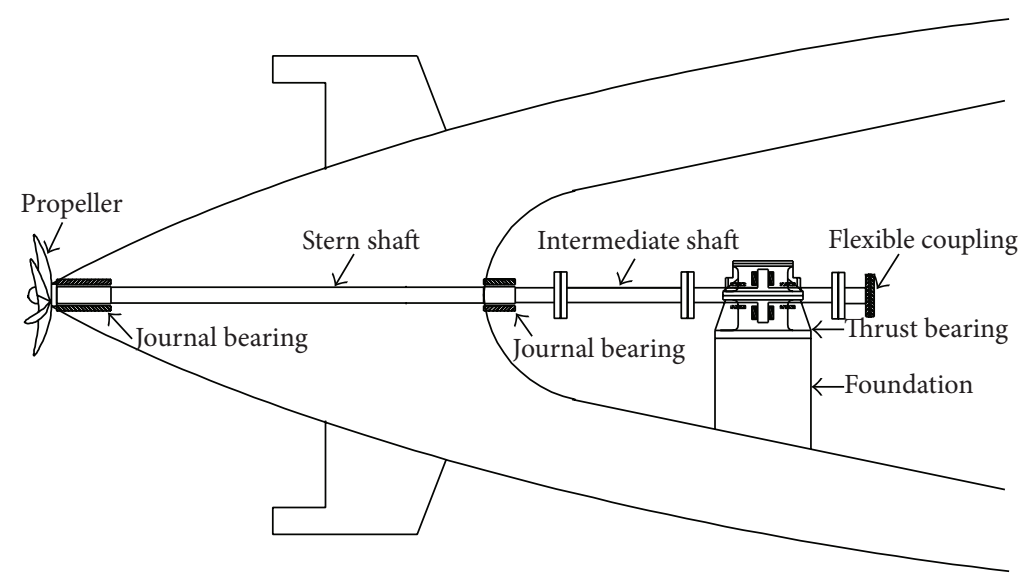

FIGURE 1: Schematic diagram of submarine propulsion shafting system.

$\rightarrow$ shafting $\rightarrow$ thrust bearing $\rightarrow$ foundation $\rightarrow$ hull. While the thrust bearing transmits propeller thrust to hull, it also provides the transmission channel of longitudinal vibration from propulsion shafting to different regions of hull, resulting in subsequent reactions of hull. Thus, the longitudinal vibration of propulsion shafting is one of the secondary excitation sources of hull vibration relative to the primary excitation sources, such as propeller, diesel generator, and auxiliary machinery [3]. It had been reported that the acoustic radiation of hull at low frequencies is associated with longitudinal vibration transmission through the propulsion shafting system $[4,5]$. Henceforth, the minimization of longitudinal vibration intensity of propulsion shafting and oscillatory thrust load transmitted to hull had received much research attention [6-11].

The study of shafting longitudinal vibration is much more complex than the torsional vibration. The reason is that in torsional vibration the vibratory system is only confined to the rotating elements [12], while in the case of longitudinal vibration, aside from the rotating elements, the fixed parts affect the vibratory behavior and must be taken into account. The values of thrust bearing mass and axial stiffness, propeller fluctuating thrust, propeller (includes entrained water) mass, axial stiffness, and damping of lubricant oil film within thrust bearing are all required to get an appropriate investigation to propulsion shafting longitudinal vibration. The fundamental studies of longitudinal vibration are evaluation of natural frequency and forced response, to verify whether the critical speed falls within the running range and the vibratory amplitude is less than the permissible value or not. When the resonance happens, the vibratory amplitude and thrust load transmitted to hull will be multiplied many times, and then the vibroacoustic response of hull will be increased greatly as well. So the avoidance of resonance is the most basic design criteria for propulsion shafting.

The propulsion shafting and hull are coupled system. Compared with the hull vibration, the longitudinal vibration of propulsion shafting is local vibration. Since the mass of propulsion shafting system is far less than the hull while the shafting nature frequency is larger than the hull, the coupled effect of hull and propulsion shafting is limited.
Hence, the propulsion shafting can be regarded as an isolated system away from the hull $[13,14]$. One important issue is the mechanic model of propulsion shafting. Formerly, the discrete model involving amounts of mass and spring units was used extensively. In general, the lumped parameter model is sufficient to estimate the 1st natural frequency as long as the determination of parameter values is accurate. However, it is a bit rough to reveal longitudinal vibration transmission in the propulsion shafting system. Thus, the continuous model of propulsion shafting is necessary to be developed.

It should be noted that the problem of propulsion shafting longitudinal vibration occurs during the shafting rotating course. Once the shafting is still, this type of vibration will be stopped immediately. That is, the propulsion shafting is rotorbearing system, and the study of longitudinal vibration must be based on the method of rotor dynamics. The propulsion shafting can be deemed as a chained structure with a branch of thrust bearing, which is particularly suitable to use the transfer matrix method (TMM) for analysis. Since firstly proposed by Prohl [15], the TMM had been proved to be one of effective methods of rotor dynamics as well as the finite element method (FEM). The TMM solves vibration problems in frequency domain with a marching procedure. Nonetheless, there exists numerical instability as the increase of trial frequency, resulting in loss of accuracy or even incorrect solution. Except that the Riccati TMM can be utilized to effectively solve this problem, the dimensionless TMM is presented to improve calculation accuracy in this paper.

Thrust bearing is the sole axial support equipment for propulsion shafting system. Virtually all marine vessels, both merchant and combat, use the sliding tilting pad thrust bearing for purpose of transmitting propeller thrust to hull [16]. One distinct difference of rotor system from nonrotor system is that the rotor system needs to be lubricated. When the thrust shaft rotates, the lubricant oil adhering to thrust collar will be continuously drawn in at the entering edges to build up wedged-shaped films of substantial carrying capacity. Since the pads are pivoted, the shape of oil film is self-aligning to correlate with the propeller thrust. The oil film not only serves as thrust transmitter, but also eliminates solid 
friction and wear between thrust collar and pads. Unlike the longitudinal vibration of rod, the dynamic characteristics of lubricant oil film between thrust collar and tilting pads must be considered in the vibratory model of propulsion shafting. So an appropriate investigation to dynamic characteristics of oil film is crucial. In early studies, a scarcity of research on this aspect was worked out due to complexity and limits of calculation tools. Schwanecke [17] and Vassilopoulos [18, 19] deduced the explicit formulas of dynamic characteristics of oil film based on the simplified infinite length bearing theory, or says the one-dimensional Reynolds equation of hydrodynamic lubrication. Although their works were comprehensive, a cursory derivation was given and the relation associated with shafting rotating speed was not covered. Iordanoff et al. [20] applied the small perturbation method to calculate stiffness and damping coefficients of air lubrication thrust bearing, which are adapted for small turbines with high rotational speeds, considering the effect of load and misalignment, but the thermal analysis of air lubricant was ignored. It means that the solutions were obtained on the basis of constant air viscosity at equivalent temperature. In this work, the detailed numerical procedures to solve dynamic coefficients of oil film within marine tilting pad thrust bearing considering thermal effect of lubricant oil are presented.

Apart from the thrust bearing itself, the axial rigidity of propulsion shafting system is also contributed by the mounting foundation of thrust bearing. So an estimation of foundation stiffness is significant to predict axial rigidity of propulsion shafting system. Due to structural complexity of foundation, the numerical estimation is made of foundation stiffness using the FEM in this paper. In all, three sets of models are analyzed to identify effects of surrounding support structure. Taken as a whole, the structural stiffness of thrust bearing is resultant value of thrust bearing unit stiffness and foundation stiffness. The influence of thrust bearing structural stiffness on dynamic characteristics of propulsion shafting longitudinal vibration, especially the 1st nature frequency and vibratory response, has reached an agreement in marine engineering. However, another factor affecting the longitudinal vibration level of propulsion shafting, which is the location of thrust bearing, has drawn little attention at present. In fact, the alteration of thrust bearing location is an effective measure to raise critical speed and reduce off-resonance response. This study is also conducted in the work. The ultimate objective of controlling propulsion shafting longitudinal vibration is to minimize thrust load transmitted to hull and underwater acoustic radiation. The results indicate that the measures of structural modification, such as reinforcement of thrust bearing structure and alternation of thrust bearing location, fail to reduce fluctuating thrust transmission from the propeller-shafting system to the hull.

\section{Transfer Matrix Model of Propulsion Shafting System}

With regard to longitudinal vibration, the journal bearings do not make stiffness and inertia contributions, so there is no necessity to be taken into account. Because of the chained characteristic of propulsion shafting system, the transfer matrix model has been established to describe dynamic behaviors. A modular representation of propulsion shafting system is given in Figure 2. The shaft of propulsion motor is not considered because of the effective isolation of flexible coupling [21-23]. The physical model has been broken into several subsystems, in which the characteristic of each subsystem is expressed by a transfer matrix.

2.1. Propeller and Flexible Coupling. The propeller is fixed at the end of stern shaft. The mass of propeller and entrained water around the propeller makes up a large proportion of the total mass of propulsion shafting system approximately $60 \%$. Thus, the propeller can be modeled as a lumped mass. Similarly, the flexible coupling is also interpreted as a lumped mass. The transfer matrixes of propeller and flexible coupling are given by

$$
\begin{aligned}
& \mathbf{T}_{p}=\left[\begin{array}{cc}
1 & 0 \\
-M_{p} \omega^{2} & 1
\end{array}\right], \\
& \mathbf{T}_{c}=\left[\begin{array}{cc}
1 & 0 \\
-M_{c} \omega^{2} & 1
\end{array}\right],
\end{aligned}
$$

where $M_{p}$ is mass of propeller and entrained water and $M_{c}$ is mass of flexible coupling.

2.2. Drive Shaft. The drive shaft is comprised of stern shaft, intermediate shaft, and thrust shaft, but the diameters of respective shaft are not consistent at all, such as the diameter of flange is much too larger than shaft neck. That is, the geometry of drive shaft is stepped. Apart from a few tiny structural defects, such as chamfer and groove, the drive shaft can be simplified as a series of uniform shafts with different diameter and length.

The transfer matrix of free-free $i$ th uniform shaft undergoing longitudinal vibration is expressed as

$$
\mathbf{T}_{s i}=\left[\begin{array}{cc}
\cos \left(k L_{i}\right) & \frac{\sin \left(k L_{i}\right)}{E S_{i} k} \\
-E S_{i} k \sin \left(k L_{i}\right) & \cos \left(k L_{i}\right)
\end{array}\right],
$$

where $S_{i}$ and $L_{i}$ represent the cross section area and length of uniform shaft, respectively, $k=\omega / c$ is the longitudinal wave number, and $c=\sqrt{E / \rho_{s}}$ is the longitudinal wave speed; $E$ is Young's modulus and $\rho_{s}$ is density. When the hysteretic damping of shafting material is considered, $E$ can be replaced by complex modulus $E\left(1+j \eta_{s}\right)$, where $\eta_{s}$ is hysteretic damping ratio.

For $n$ numbers of uniform shafts making up of the drive shaft in series, the combined characteristic is given by backward matrix multiplication of all uniform shafts; that is,

$$
\mathbf{T}_{s}=\mathbf{T}_{s n} \cdots \mathbf{T}_{s 2} \mathbf{T}_{s 1} .
$$

2.3. Thrust Bearing and Foundation. To some extent, the thrust bearing and foundation can be divided into liquid part of lubricant oil film and solid part of steel structure. 


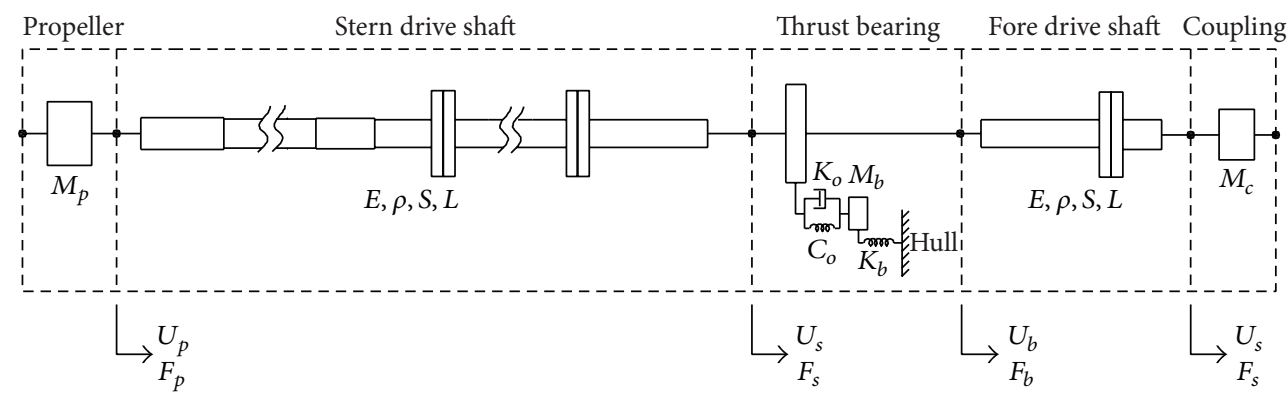

FIGURE 2: Modular representation of propulsion shafting system.

The thrust bearing is independently mounted on foundation via bolts rigidly in submarines. It means that the thrust bearing and foundation provide axial support for propulsion shafting system together or the thrust bearing and foundation are two sources of axial rigidity in propulsion shafting system.

The thrust bearings of submarine are those of Michell type and Kingsbury type, of which the distinct difference is the supporting form of pivoted pads. The dynamic characteristic of thrust bearing is complicated because of its irregular configuration. Taking, for example, the Kingsbury thrust bearing, by tracing the load path, it is made up of thrust collar, pads, buttons, upper leveling links, lower leveling links, retainer ring, and house. The structural stiffness of thrust bearing unit can be obtained by computing the total flexibility. With proper simplification, the individual flexibility of various components can be calculated although the geometry of these components is irregular. Since these components are connected in series, all flexibilities are summed to get the total flexibility. This theoretical method was firstly proposed by Vassilopoulos and Hamilton [19]. Certainly, the more accurate value of thrust bearing stiffness can be obtained by static experiment test on pedestal.

The preceding description is confined to the stiffness generated by thrust bearing unit, but it does not incorporate the stiffness generated by foundation. Actually, the dominant factor of deciding whether thrust bearing structure is rigid or flexible is the foundation spring constant. The details of estimating foundation stiffness are described in Section 4.

The following expression is made:

$$
\frac{1}{K_{b}}=\frac{1}{K_{t}}+\frac{1}{K_{f}}
$$

where $K_{t}$ and $K_{f}$ are axial structural stiffness of thrust bearing unit and foundation, respectively, and $K_{b}$ is resultant stiffness.

The oil film between thrust collar and tilting pads is modeled as linear spring stiffness $K_{o}$ and damping $C_{o}$; the steel structure of thrust bearing and foundation is represented as linear spring stiffness $K_{b}$ and lumped mass $M_{b}$, as shown in Figure 2. To allow for structural damping, the complex stiffness $K_{b}\left(1+j \eta_{b}\right)$ is alternative, where $\eta_{b}$ is loss factor. Thus,

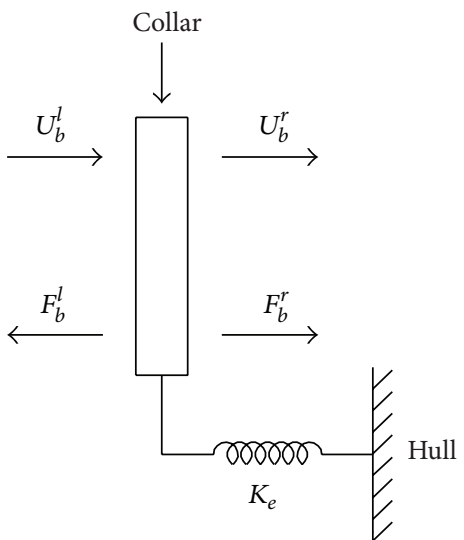

FIGURE 3: Equivalent mechanic model of thrust bearing and foundation.

the transfer matrix equation of thrust bearing and foundation can be expressed as

$$
\left\{\begin{array}{l}
U^{r} \\
F^{r}
\end{array}\right\}=\left[\begin{array}{cc}
1 & \frac{1}{K_{b}} \\
0 & 1
\end{array}\right]\left[\begin{array}{cc}
1 & 0 \\
-M_{b} \omega^{2} & 1
\end{array}\right]\left[\begin{array}{cc}
1 & \frac{1}{K_{o}+j \omega C_{o}} \\
0 & 1
\end{array}\right]\left\{\begin{array}{l}
U^{l} \\
F^{l}
\end{array}\right\},
$$

where the superscripts " $r$ " and " $l$ " denote the right end and the left end.

The hull is interpreted as the rigid boundary condition. With introduction of $U^{r}=0,(5)$ is manipulated as

$$
F^{l}=-\frac{\left(K_{b}-M_{b} \omega^{2}\right)\left(K_{o}+j \omega C_{o}\right)}{K_{b}-M_{b} \omega^{2}+K_{o}+j \omega C_{o}} U^{l}=K_{e} U^{l}
$$

where $K_{e}$ represents the equivalent stiffness of thrust bearing and foundation.

Then the thrust bearing and foundation are visualized as a spring attached to thrust collar in Figure 3.

The magnitude of thrust collar axial stiffness reaches $10^{11}$, which amounts to that of a rigid body. The relationship between state variables in the left and right sides of thrust collar has the following form:

$$
\begin{aligned}
& U_{b}^{r}=U_{b}^{l}, \\
& F_{b}^{r}=M_{o} \ddot{U}_{b}^{l}+K_{e} U_{b}^{l}+F_{b}^{l},
\end{aligned}
$$

where $M_{o}$ is mass of thrust collar. 
Substitution of expression $U_{b}^{l}=U e^{j \omega t}$ into (7) yields

$$
\mathbf{T}_{b}=\left[\begin{array}{cc}
1 & 0 \\
-M_{o} \omega^{2}+K_{e} & 1
\end{array}\right],
$$

where $\mathbf{T}_{b}$ is the transfer matrix of thrust bearing and foundation.

2.4. Dimensionless Transfer Matrix. For dimensional TMM, the deviation accumulates as the increase of trial frequency because of large numbers in transfer matrix, which affects accuracy of results seriously. The error can be eliminated by transforming the dimensional transfer matrix to the dimensionless form. Introducing the following transformation of state vector:

$$
\left\{\begin{array}{l}
U \\
F
\end{array}\right\}=\left[\begin{array}{cc}
L & 0 \\
0 & E S
\end{array}\right]\left\{\begin{array}{l}
\bar{U} \\
\bar{F}
\end{array}\right\}=\mathbf{S}\left\{\begin{array}{l}
\bar{U} \\
\bar{F}
\end{array}\right\},
$$

where the symbol "-_ denotes dimensionless variables (the same below), $\mathbf{S}$ is transformation matrix.

By substitution of (9) into dimensional transfer matrix equation, the dimensionless transfer matrix is derived as

$$
\overline{\mathbf{T}}=\mathbf{S}^{-1} \mathbf{T S},
$$

where $\mathbf{T}$ is dimensional transfer matrix.

By replacing $\mathbf{T}$ in (10) by transfer matrix of respective subsystem of propulsion shafting, the following dimensionless transfer matrixes are obtained:

$$
\begin{aligned}
& \overline{\mathbf{T}}_{p}=\left[\begin{array}{cc}
1 & 0 \\
-\frac{M_{p} \omega^{2} L}{E S} & 1
\end{array}\right], \\
& \overline{\mathbf{T}}_{s i}=\left[\begin{array}{cc}
\cos \left(k L_{i}\right) & \frac{\sin \left(k L_{i}\right)}{k L_{i}} \\
-k L_{i} \sin \left(k L_{i}\right) & \cos \left(k L_{i}\right)
\end{array}\right], \\
& \overline{\mathbf{T}}_{b}=\left[\begin{array}{cc}
\left(-M_{o} \omega^{2}+K_{e}\right) L & 1 \\
E S & 0
\end{array}\right], \\
& \overline{\mathbf{T}}_{c}=\left[\begin{array}{cc}
1 & 0 \\
-\frac{M_{c} \omega^{2} L}{E S} & 1
\end{array}\right] .
\end{aligned}
$$

One problem in application of the above dimensionless transfer matrixes is that lumped mechanical elements, such as propeller and flexible coupling, have no geometrical parameters. To overcome this difficulty, the cross section area and length of adjacent uniform shaft are utilized as nominal cross section area and length of those lumped parts.

The relationship between state vector of the right and left ends of propulsion shafting can be written as

$$
\left\{\begin{array}{l}
\bar{U}^{r} \\
\bar{F}^{r}
\end{array}\right\}=\left[\begin{array}{ll}
\bar{T}_{11} & \bar{T}_{12} \\
\bar{T}_{21} & \bar{T}_{22}
\end{array}\right]\left\{\begin{array}{c}
\bar{U}^{l} \\
\bar{F}^{l}
\end{array}\right\},
$$

where $\bar{T}_{11}, \bar{T}_{12}, \bar{T}_{21}$, and $\bar{T}_{22}$ are variables of accumulated dimensionless transfer matrix obtained by backward matrix multiplication of all subsystems.

According to the mechanic model of propulsion shafting shown in Figure 2, the boundary conditions of both ends are free; that is, $\bar{F}^{r}=0$ and $\bar{F}^{l}=0$. So $\bar{T}_{21}$ is the surplus variable. By sweeping frequency, the trial frequencies which meet expression $\bar{T}_{21}=0$ are those natural frequencies of propulsion shafting longitudinal vibration. When the natural frequency is confirmed, the corresponding mode shape can also be deduced.

2.5. Expanded Transfer Matrix. To calculate vibratory response of propulsion shafting excited by propeller fluctuating thrust, the transfer matrix of respective subsystem still needs to be expanded. The transfer matrix equation of propeller excited by thrust load is written as

$$
\left\{\begin{array}{c}
U_{p}^{r} \\
F_{p}^{r}
\end{array}\right\}=\left[\begin{array}{cc}
1 & 0 \\
-M_{p} \omega^{2} & 1
\end{array}\right]\left\{\begin{array}{c}
U_{p}^{l} \\
F_{p}^{l}
\end{array}\right\}+\left\{\begin{array}{c}
0 \\
F_{p}
\end{array}\right\},
$$

where $F_{p}$ is propeller fluctuating thrust.

Equation (13) is easily expanded as

$$
\left\{\begin{array}{c}
U_{p}^{r} \\
F_{p}^{r} \\
1
\end{array}\right\}=\left[\begin{array}{ccc}
1 & 0 & 0 \\
-M_{p} \omega^{2} & 1 & F_{p} \\
0 & 0 & 1
\end{array}\right]\left\{\begin{array}{c}
U_{p}^{l} \\
F_{p}^{l} \\
1
\end{array}\right\}=\mathrm{Te}_{p}\left\{\begin{array}{c}
U_{p}^{l} \\
F_{p}^{l} \\
1
\end{array}\right\},
$$

where $\mathbf{T e}_{p}$ is the expanded transfer matrix of propeller.

Similarly, the expanded transfer matrixes of subsequent subsystems can be deduced with the same procedures, which are represented by $\mathbf{T e}_{s s}, \mathbf{T e}_{b}, \mathbf{T e}_{s f}$, and $\mathbf{T e}_{c}$, respectively. But the only difference is that there is no force term in these expanded matrixes compared with that of propeller, because the thrust only acts on the propeller directly.

Then, the accumulated expanded transfer matrix of the complete propulsion shafting system is given by backward matrix multiplication of all subsystems:

$$
\mathbf{T e}=\mathbf{T e}_{c} \mathbf{T e}_{s f} \mathbf{T e}_{b} \mathbf{T e}_{s s} \mathbf{T e}_{p} .
$$

Combined with the free-free boundary conditions, the solution of propeller response is

$$
U_{p}=-\frac{T e_{23}}{T e_{21}},
$$

where $T e_{21}$ and $T e_{23}$ are the first and third elements in the second row of matrix Te, respectively.

When the propeller reaction is determined, the vibratory response of the whole propulsion shafting system can be solved. And then the dynamic force of oil film and thrust load transmitted to hull are, respectively, given by

$$
\begin{aligned}
& F_{o}=\left(K_{o}+j \omega C_{o}\right)\left(U_{o}-U_{b}\right), \\
& F_{b}=K_{b} U_{b},
\end{aligned}
$$


where $U_{o}$ and $U_{b}$ are responses of thrust collar and thrust bearing, respectively.

As one of the most important indexes of measuring propeller fluctuating thrust acting on hull through the propulsion shafting system, the force transmissibility is then easily obtained by $F_{b} / F_{p}$.

\section{Dynamic Characteristics of Lubricant Oil Film}

The values of propeller mass, structural stiffness, and lumped mass of thrust bearing, stiffness, and damping of lubricant oil film within thrust bearing are all necessary to determine characteristics of propulsion shafting longitudinal vibration. These values are easily got from producers except the dynamic parameters of oil film. The longitudinal vibration of thrust collar squeezes the oil film, resulting in the variation of film thickness at the equilibrium. Generally, this variation is so small that the small perturbation method can be used to calculate the stiffness and damping coefficients of oil film combined with hydrodynamic lubrication theory.

As is shown in Figure 4, thrust bearing is constructed with two rows of pads; one row is designed for driving ahead and the other is for driving astern. In Figure $4, O$ and $O_{p}$ are geometrical center of pad and supporting center, respectively, $\varphi$ is central angle of pad, $\gamma_{p}$ is tilting angle of pad around its supporting line connected with points $O$ and $O_{p}, r_{i}$ and $r_{o}$ are inner and outer radius of pad, respectively, $b=r_{o}-r_{i}$ is width, and $r_{p}$ and $\theta_{p}$ are radial and circumferential coordinates of the supporting center $O_{p}$, respectively. Because of the circumference symmetry of tilting pads with respect to thrust collar, the geometrical shape and lubricating property of oil film between thrust collar and individual pad is completely the same. That is, the cycle is $2 \pi / Z$, where $Z$ is the number of pads. Thus, just the oil film between thrust collar and one pad is taken as study object.

3.1. Solution of Static Characteristics. The static characteristics of oil film, including distribution of thickness, viscosity, pressure, and temperature, are obtained by solving two equations of Reynolds and energy as well as two expressions of film thickness and lubricant oil viscosity temperature, simultaneously.

The steady Reynolds equation in cylindrical coordinate is expressed in dimensionless form as [24]

$$
\frac{\partial}{\partial R}\left(\frac{R H^{3}}{U} \frac{\partial P}{\partial R}\right)+\frac{1}{R} \frac{\partial}{\partial \theta}\left(\frac{H^{3}}{U} \frac{\partial P}{\partial \theta}\right)=6 R \frac{\partial H}{\partial \theta},
$$

where the dimensionless parameters are as follows: $R$ is radial coordinate; $\theta$ is circumferential coordinate; $P$ is pressure; $H$ is film thickness; $U$ is viscosity.

The energy equation is similarly written as [24]

$$
\begin{aligned}
(6 & \left.-\frac{H^{2}}{U R^{2}} \frac{\partial P}{\partial \theta}\right) \frac{\partial T}{\partial \theta}-\frac{H^{2}}{U} \frac{\partial P}{\partial R} \frac{\partial T}{\partial R} \\
& =\frac{12 \mu_{0} b^{2} \omega}{c_{o} \rho_{o} h_{m}^{2} t_{0}}\left\{\frac{U R^{2}}{H^{2}}+\frac{H^{2}}{12 U}\left[\left(\frac{\partial P}{R \partial \theta}\right)^{2}+\left(\frac{\partial P}{\partial R}\right)^{2}\right]\right\},
\end{aligned}
$$

where $T$ is temperature, $\omega$ is angular speed, $c_{o}$ and $\rho_{o}$ are specific heat capacity and density of lubricant oil, respectively, $h_{m}$ is minimum film thickness, and $\mu_{0}$ is viscosity of lubricant oil corresponding to inlet temperature $t_{0}$.

The preceding two equations are derived from the conventional form of the equations by means of the following substitutions:

$$
\begin{gathered}
R=\frac{r}{b}, \quad H=\frac{h}{h_{m}}, \quad U=\frac{\mu}{\mu_{0}}, \\
P=\frac{p h_{m}^{2}}{\mu_{0} \omega b^{2}}, \quad T=\frac{t}{t_{0}},
\end{gathered}
$$

where $r, h, \mu, p$, and $t$ are dimensional parameters corresponding to dimensionless parameters $R, H, U, P$, and $T$, respectively.

The expression of film thickness can be deduced from the geometrical shape of oil film and is given by

$$
H=1+\frac{\gamma_{p} b}{h_{m}}\left[R \sin \left(\theta_{p}-\theta\right)-R_{m} \sin \left(\theta_{p}-\theta_{m}\right)\right],
$$

where $\left(R_{m}, \theta_{m}\right)$ is coordinate of the minimum thickness $h_{m}$.

In the end, there is necessity to add the expression of lubricant oil viscosity temperature. Here, the Walther equation is used directly [24]:

$$
\operatorname{lglg}\left(\frac{\mu_{0}}{\rho_{o}} U+0.6\right)=A-B \lg \left(t_{0} T+273.15\right),
$$

where $A$ and $B$ are constants determined by two sets of viscosity and temperature values.

Note that the two equations of Reynolds and energy are coupled; there is no possibility to obtain analytic solution, but the numerical solution can be solved. With the finite difference algorithm, the oil film attached to the surface of pad is divided into a mesh pattern, as shown in Figure 5. As long as the mesh scale is not too large, the static characteristics of oil film can be represented by these mesh points.

Then, the two partial differential equations of Reynolds and energy are reduced to two sets of algebraic equations. With introduction of boundary conditions of pressure and temperature, the two algebraic equations are solved by an iterative procedure until the results meet defined convergence criteria. It should be pointed out that not all convergent solutions are actual static characteristics of oil film except that they meet additional two conditions; that is, the load capacity of oil film must balance with propeller steady thrust and the moment to supporting center is equal to zero. The load capacity and moment of oil film can be solved by the following formulas. By using the Simpson formula in numerical integration, it is easy to turn the integrals into the sums:

$$
\begin{aligned}
& F_{t}=Z \int_{0}^{\varphi} \int_{r_{i}}^{r_{o}} p r \mathrm{~d} r \mathrm{~d} \theta \\
& M=\int_{0}^{\varphi} \int_{r_{i}}^{r_{o}} p r^{2} \sin \left(\theta_{p}-\theta\right) \mathrm{d} r \mathrm{~d} \theta .
\end{aligned}
$$



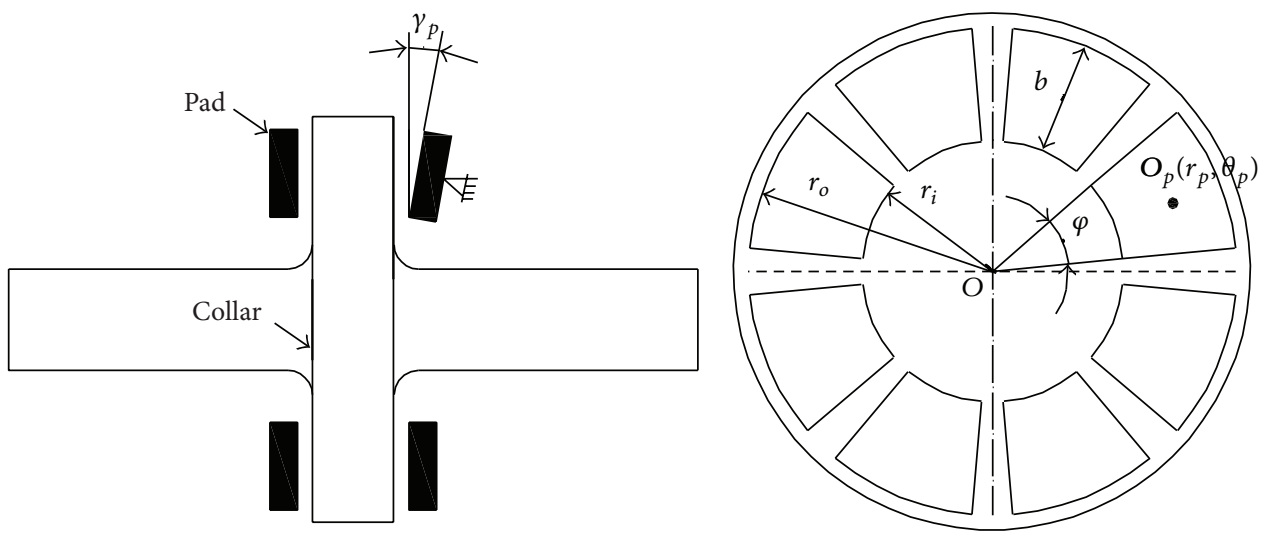

FIGURE 4: Schematic diagram of thrust bearing.
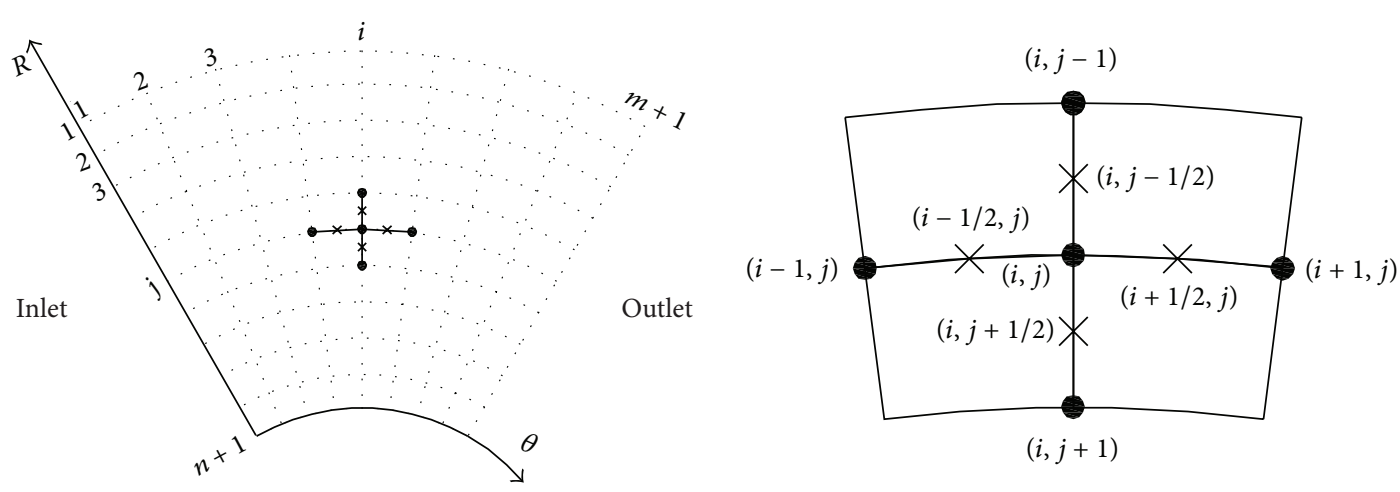

FiguRE 5: Mesh pattern of oil film.

The relationship between propeller steady thrust and shafting rotating speed can be established as

$$
T_{p}=K_{T} \rho_{w} n^{2} D^{4},
$$

where $\rho_{w}$ is water density, $n$ is rotational speed, $D$ is propeller diameter, and $K_{T}$ is thrust coefficient obtained by open-water test of propeller.

Due to a scarcity of test data of the thrust coefficient $K_{T}$ at hand, a constant is chosen as an initial approximation. Thus, the propeller steady thrust is proportional to square of rotational speed and can be made

$$
T_{p}=T_{e}\left(\frac{n}{n_{e}}\right)^{2}
$$

where $T_{e}$ is rated propeller steady thrust and $n_{e}$ is rated rotational speed.

The detailed numerical procedures are presented in the appendix.

3.2. Dynamic Characteristic Calculation. By setting $H_{0}$ is the dimensionless film thickness at the equilibrium and $\Delta H$ is the dimensionless perturbation, the dynamic film thickness is

$$
H=H_{0}+\Delta H \text {. }
$$

Assuming that the magnitude of perturbation is small, a first-order expansion of the oil film dynamic pressure can be made:

$$
P=P_{0}+\left(\frac{\partial P}{\partial H}\right)_{0} \Delta H+\left(\frac{\partial P}{\partial \dot{H}}\right)_{0} \Delta \dot{H},
$$

where the symbol " ()$_{0}$ " denotes the partial derivative at the equilibrium.

And then, the dimensionless stiffness and damping of oil film can be obtained by area integral of dynamic pressure in expression (27):

$$
\begin{aligned}
K & =\int_{0}^{\varphi} \int_{R_{i}}^{R_{o}}\left(\frac{\partial P}{\partial H}\right)_{0} R \mathrm{~d} R \mathrm{~d} \theta, \\
C & =\int_{0}^{\varphi} \int_{R_{i}}^{R_{o}}\left(\frac{\partial P}{\partial \dot{H}}\right)_{0} R \mathrm{~d} R \mathrm{~d} \theta .
\end{aligned}
$$

For dynamic analysis, the term of squeezing oil film must be added in the steady Reynolds equation (18); that is

$$
\frac{\partial}{\partial R}\left(\frac{R H^{3}}{U} \frac{\partial P}{\partial R}\right)+\frac{1}{R} \frac{\partial}{\partial \theta}\left(\frac{H^{3}}{U} \frac{\partial P}{\partial \theta}\right)=6 R \frac{\partial H}{\partial \theta}+12 R \frac{\partial H}{\partial t} .
$$


TABLE 1: Parameters of thrust bearing.

\begin{tabular}{lcc}
\hline Parameter & Symbol & Value \\
\hline Tilting pad & & \\
$\quad$ Inner radius $(\mathrm{mm})$ & $r_{i}$ & 165 \\
Outer radius $(\mathrm{mm})$ & $r_{o}$ & 325 \\
Central angle $(\mathrm{rad})$ & $\varphi$ & 0.70 \\
$\quad$ Number & $Z$ & 8 \\
Supporting center & & \\
Radial coordinate $(\mathrm{mm})$ & $r_{p}$ & 245 \\
Circumferential coordinate $(\mathrm{rad})$ & $\theta_{p}$ & 0.405 \\
Lubricant oil & & \\
Density $\left(\mathrm{km} / \mathrm{m}^{3}\right)$ & $\rho_{o}$ & 890 \\
Specific heat capacity $\left(\mathrm{J} / \mathrm{kg} \cdot{ }^{\circ} \mathrm{C}\right)$ & $c_{o}$ & 1922.8 \\
Inlet temperature $\left({ }^{\circ} \mathrm{C}\right)$ & $t_{0}$ & 35 \\
Viscosity $(\mathrm{Pa} \cdot \mathrm{s})$ & $\mu_{0}$ & 0.051 \\
\hline
\end{tabular}

By substitutions of pressure and film thickness by the expressions (26) and (27), the following two partial differential equations are deduced by keeping only the first-order terms:

$$
\begin{gathered}
\frac{\partial}{\partial R}\left(\frac{R H_{0}^{3}}{U} \frac{\partial}{\partial R}\left(\frac{\partial P}{\partial H}\right)_{0}\right)+\frac{1}{R} \frac{\partial}{\partial \theta}\left(\frac{H_{0}^{3}}{U} \frac{\partial}{\partial \theta}\left(\frac{\partial P}{\partial H}\right)_{0}\right) \\
=-\frac{\partial}{\partial R}\left(\frac{3 R H_{0}^{2}}{U} \frac{\partial P_{0}}{\partial R}\right)-\frac{1}{R} \frac{\partial}{\partial \theta}\left(\frac{3 H_{0}^{2}}{U} \frac{\partial P_{0}}{\partial \theta}\right), \\
\frac{\partial}{\partial R}\left(\frac{R H_{0}^{3}}{U} \frac{\partial}{\partial R}\left(\frac{\partial P}{\partial \dot{H}}\right)_{0}\right)+\frac{1}{R} \frac{\partial}{\partial \theta}\left(\frac{H_{0}^{3}}{U} \frac{\partial}{\partial \theta}\left(\frac{\partial P}{\partial \dot{H}}\right)_{0}\right)=12 R .
\end{gathered}
$$

Note that the forms of the above two equations in the left sides are the same as the steady Reynolds equation, in which just $P$ is replaced by $(\partial P / \partial H)_{0}$ and $(\partial P / \partial \dot{H})_{0}$, respectively. Thus, the two equations can be solved with the same numerical algorithm as that of steady Reynolds equation. The obtained $(\partial P / \partial H)_{0}$ and $(\partial P / \partial \dot{H})_{0}$ give the solutions of the dimensionless stiffness and damping of oil film in (28) directly, and then the actual stiffness and damping of oil film are solved by

$$
\begin{aligned}
& K_{o}=\frac{\mu_{0} \omega b^{4}}{h_{m}^{3}} K, \\
& C_{o}=\frac{\mu_{0} b^{4}}{h_{m}^{3}} C .
\end{aligned}
$$

It can be observed that the dynamic characteristics of oil film are determined by geometry size of pad $(b)$, property of lubricant oil $\left(\mu_{0}\right)$, minimum film thickness $\left(h_{m}\right)$, and rotational speed $(\omega)$.

\subsection{Results. The parameters of tilting pad thrust bearing are} summarized in Table 1.

A program to solve dynamic characteristics of lubricant oil film has been devised on the platform of MATLAB. Since

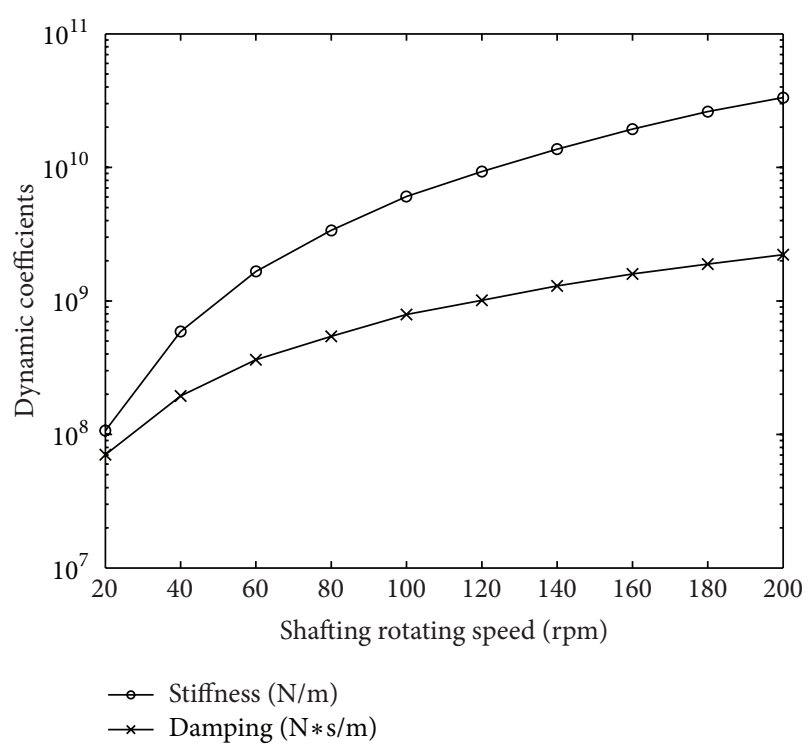

FIGURE 6: Stiffness and damping of oil film.

the propeller steady thrust correlates with shafting rotating speed, the dynamic characteristics of oil film must be a function of rotational speed as well. The results are given in Figure 6. It clearly shows the nonlinear relationship between dynamic characteristics of oil film and shafting rotating speeds. More exactly to say, the stiffness and damping of oil film keep pace with the increase of shafting rotating speed nonlinearly. Usually, the oil film stiffness is not less than that of thrust bearing steel structure. In terms of the thrust bearing unit, the influence of oil film on global stiffness is lessened as the rotational speed rises. Especially, the changeability of global stiffness is weak at high rotational speeds. Then, the recommendation proposed by bearing's producer of a spring constant for thrust bearing unit, which is independent of rotational speed and thrust, is feasible.

The calculation of stiffness and damping of oil film is a complicated task, in which a large amount of work concentrates on the solution of static characteristics. For simplification, one approach used previously is to replace the distribution of film viscosity by an equivalent viscosity at thermal equilibrium temperature [24]. In this case, the solution of energy equation can be avoided. The formula of thermal equilibrium temperature is

$$
t_{e}=t_{0}+\alpha \frac{p_{o}}{c_{o} \rho_{o} q_{o}}
$$

where $\alpha$ is correction factor. For low-speed bearing, the factor can be set equal to $0.8 . p_{o}$ and $q_{o}$ are friction power and lubricant oil flow, respectively, which can be solved by

$$
\begin{aligned}
& p_{o}=\int_{0}^{\varphi} \int_{r_{i}}^{r_{o}}\left(-\frac{h}{2} \frac{\partial p}{\partial \theta}-\frac{\mu r^{2} \omega}{h}\right) r \omega \mathrm{d} r \mathrm{~d} \theta, \\
& q_{o}=\int_{r_{i}}^{r_{o}}\left(-\frac{h^{3}}{12 \mu} \frac{\partial p}{r \partial \theta}+\frac{1}{2} h r \omega\right) \mathrm{d} r+\int_{0}^{\varphi}\left(-\frac{h^{3}}{12 \mu} \frac{\partial p}{\partial r}\right) r \mathrm{~d} \theta .
\end{aligned}
$$


TABLE 2: Calculated stiffness and damping of oil film based upon equivalent viscosity and variable viscosity.

\begin{tabular}{lcccc}
\hline Shafting rotating speed $(\mathrm{rpm})$ & 40 & 60 & 80 & 100 \\
\hline Stiffness $\left(\times 10^{9} \mathrm{~N} / \mathrm{m}\right)$ & & & & \\
$\quad$ Variable viscosity & 0.59 & 1.66 & 3.38 & 6.06 \\
$\quad$ Equivalent viscosity & 0.63 & 2.09 & 4.51 & 7.80 \\
Damping $\left(\times 10^{8} \mathrm{~N} / \mathrm{m}\right)$ & & & & \\
$\quad$ Variable viscosity & 1.94 & 3.63 & 5.43 & 7.90 \\
Equivalent viscosity & 2.83 & 9.20 & 16.14 & 22.32 \\
\hline
\end{tabular}

Here, the results at typical shafting rotating speeds based upon equivalent viscosity and variable viscosity are compared in Table 2. As can be seen, the thermal effect is prone to decrease the stiffness and damping of oil film. One straightforward explanation is that the distribution of film temperature and viscosity is so nonuniform that this simplification is relatively approximate. The more important reason is that the minimum film thickness obtained by equivalent viscosity is less than the solution corresponding to variable viscosity under the same propeller steady thrust. Because of the negative correlation between dynamic coefficients of oil film and minimum film thickness, the calculated stiffness and damping of oil film with equivalent viscosity are certainly greater. The results indicate that the thermal effect should be considered for dynamic analysis of oil film.

\section{Stiffness of Thrust Bearing Foundation}

To estimate the longitudinal vibration level in propulsion shafting system, it is desirable to know the axial stiffness of thrust bearing foundation in as-built condition. The foundation is typical welding assembly made up of plates. Briefly, the axial stiffness of foundation is the result of bend and shear deflection of plates relative to hull, particularly the reaction of shear, at the excitation of thrust load. Because of the continuity of supporting structure, the surrounding structure also contributes to foundation stiffness. For such complex structure, analytical method is not deemed to provide sufficiently accurate solution. It is therefore decided to resort to the finite element method (FEM), and the commercial finite element software ANSYS is used.

In view of acoustic design, the foundation may be made as rigid as desired. Also, to guarantee the normal operation of thrust bearing, the stiffness of foundation should be sufficient. In fact, the measure of thrust bearing independently mounted is to achieve a much more rigid system in the axial direction. From the point of extensive modifications envisioned necessary to solve the problem of insufficient foundation stiffness, there is necessity to be aware of effect in any proposed modifications to stiffen the foundation.

4.1. Original Foundation. Since the stern hull plays major role in supporting the foundation and reacting to the propeller thrust excitation, the structural behavior of foundation can be analyzed by considering this aft portion of hull. The finite element model of stern hull including foundation and supporting structure, named Model 1, is shown in Figure 7. The model is comprised of plates and rib stiffeners, which are represented by SHELL63 elements and BEAM188 elements, respectively [25]. The rib section on the hull is of $\mathrm{T}$ shape, while on the pedestal of foundation it is of $\mathrm{L}$ shape. The thicknesses of face plate, web plate, and knee plate of foundation are $26 \mathrm{~mm}, 20 \mathrm{~mm}$, and $12 \mathrm{~mm}$, respectively.

In order to identify contribution of various parts to foundation rigidity, additional two models are formulated, named Model 2 and Model 3, respectively. Figure 8 presents the two models, in which Model 2 is the foundation itself and Model 3 also includes the pedestal of foundation.

With Hooker theorem, the axial stiffness of foundation can be obtained by loading in axial direction and measuring the corresponding deformation. Since the thrust bearing is mounted on foundation with bolts, the propeller thrust is transmitted to foundation as the form of lumped force at the location of each bolt. Therefore, the static load is distributed equally over eight nodes laying four nodes each on the two surfaces of the foundation. In each case, a total axial force of $1 \times 10^{5} \mathrm{~N}$ is applied.

The assignment of boundary conditions is crucial. For Model 1, all zero translations are located at the nodes in front of hull. For Model 2, only the axial translation is constrained to zero for the nodes lying on the bottom of plates. For Model 3, all translations are constrained to zero and all rotations are free for the nodes lying on the bottom due to constraints of hull. With these applied boundary conditions, the axial displacement of nodes at the location of bolts is measured. By taking the average of these node deformations, the axial stiffness of three models is evaluated, which is $8.233 \times 10^{8} \mathrm{~N} / \mathrm{m}, 5.046 \times 10^{9} \mathrm{~N} / \mathrm{m}$, and $8.299 \times 10^{8} \mathrm{~N} / \mathrm{m}$, respectively. By comparison, the rigidity of foundation itself is sufficient, but the surrounding structure connected with foundation, particularly the pedestal, is relatively flexible. The axial stiffness of marine thrust bearing unit is generally more than $1 \times 10^{9} \mathrm{~N} / \mathrm{m}$; it means that the thrust bearing unit is stiffer than the mounting foundation, which should not occur in ships if possible. The results of Model 1 and Model 3 indicate that the hull makes little contribution to foundation stiffness, while the pedestal affects the rigidity of foundation greatly. That is, Model 3 is accurate enough to estimate stiffness of thrust bearing foundation.

4.2. Reinforced Foundation. The foundation stiffness should not be much too less than that of thrust bearing unit from viewpoint of vibration control. The foundation and pedestal are vertical structure like a hollow cantilever box. Under the action of thrust, the static deformation decreases gradually from the top to the bottom. To stiffen the foundation greatly, the measure of thickening plates is not always effective. For instance, when the plate thickness of pedestal increases $8 \mathrm{~mm}$, the foundation stiffness is only $1.014 \times 10^{9} \mathrm{~N} / \mathrm{m}$, or an increase of approximately $22.2 \%$. Obviously, this improvement is limited. The effort of thickening plates does not achieve the prospective objective of reinforced foundation. It seems that it is not technically feasible to increase the foundation stiffness 


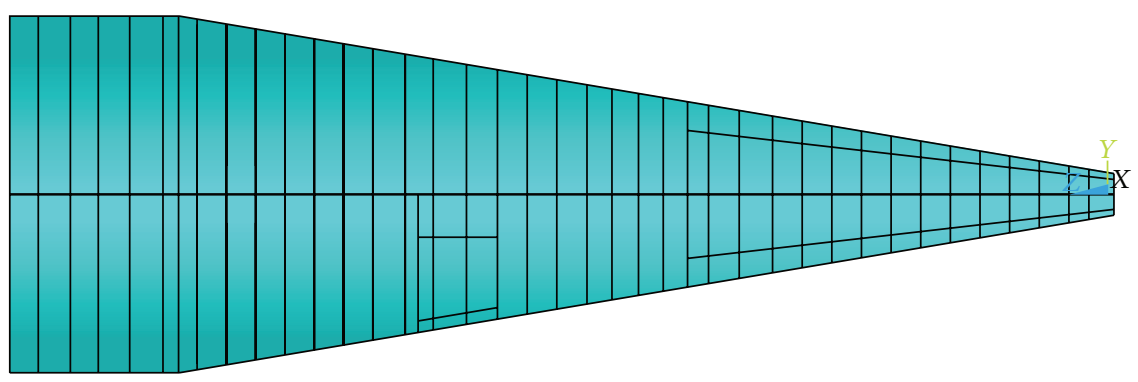

(a) Profile

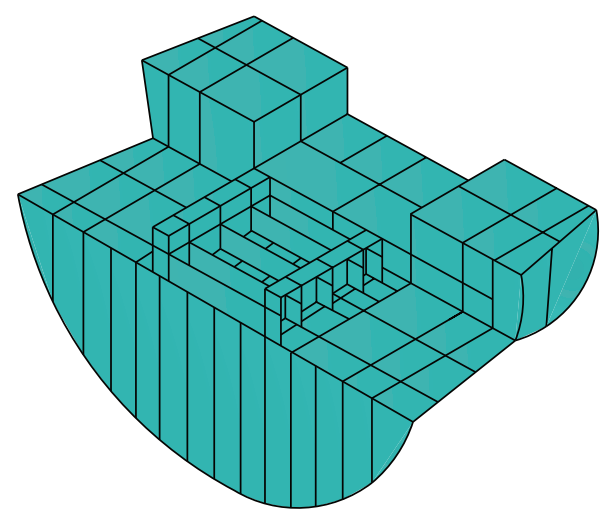

(c) Foundation and supporting structure

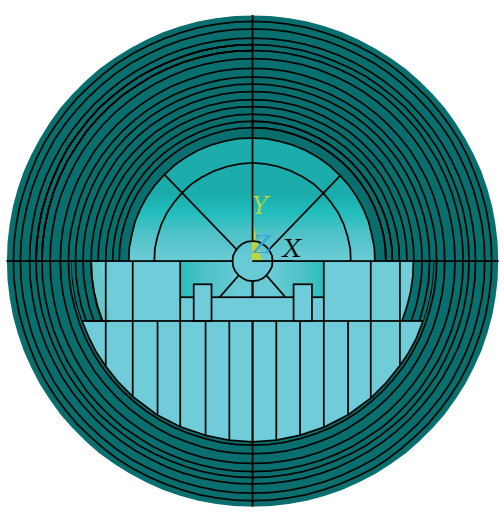

(b) Front view

FIGURE 7: Illustration of Model 1.

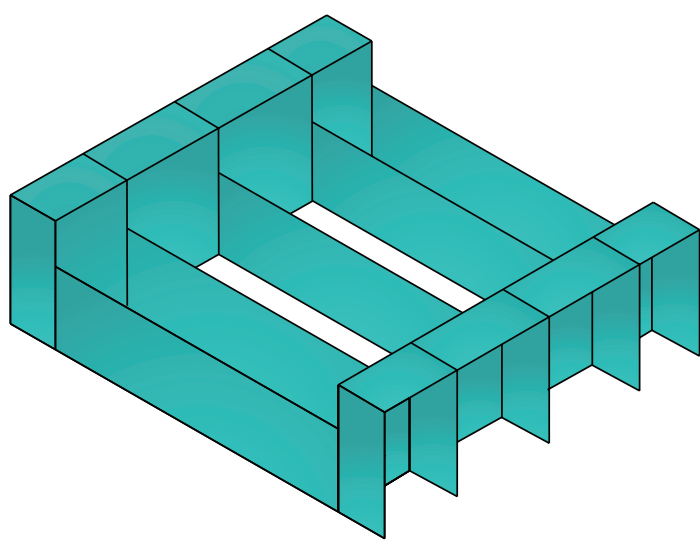

(a) Model 2

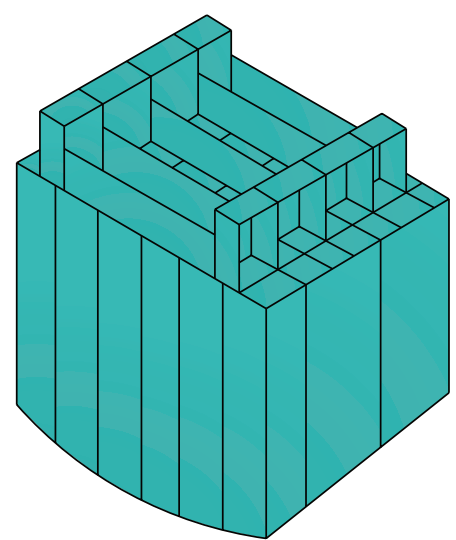

(b) Model 3

Figure 8: Illustrations of Model 2 and Model 3.

largely without drastic changes in structural configuration of foundation.

Thus, the efforts are directed toward modifying the internal structural configuration of pedestal. One evident shortcoming of the original internal structural configuration of pedestal is that the stiffeners are almost concentrated on the top, while the bottom seems to be relatively flexible. With reasonable supplement added in this area, the total stiffness of foundation will be improved substantially. One proposed modified internal structural configuration is demonstrated in Figure 9, in which the original is also given. The modification includes deletion of local stiffeners and addition of longitudinal and transverse plates. These plates are all extended to connect with adjacent plates. The calculated axial stiffness of the modified foundation is found to be $1.237 \times$ $10^{9} \mathrm{~N} / \mathrm{m}$, or an increase of $49.05 \%$ compared with the original $8.299 \times 10^{9} \mathrm{~N} / \mathrm{m}$. The result validates the effectiveness of this integrated reinforced scheme. 
TABLE 3: Parameters of propulsion shafting system.

\begin{tabular}{lcc}
\hline Parameter & Symbol & Value \\
\hline Density $\left(\mathrm{kg} / \mathrm{m}^{3}\right)$ & $\rho_{s}$ & 7850 \\
Young's modulus $(\mathrm{GPa})$ & $E$ & 2.0 \\
Propeller (includes entrained water) mass $(\mathrm{kg})$ & $M_{p}$ & 7150 \\
Flexible coupling mass $(\mathrm{kg})$ & $M_{c}$ & 1300 \\
Thrust collar mass $(\mathrm{kg})$ & $M_{o}$ & 445 \\
Thrust bearing mass $(\mathrm{kg})$ & $M_{b}$ & 4435 \\
Thrust bearing resultant stiffness $(\mathrm{MN} / \mathrm{m})$ & $K_{b}$ & 1100 \\
\hline
\end{tabular}

The reinforced foundation has significant effect to improve resultant stiffness of thrust bearing. Regarding assembly structure, the total stiffness depends on individual stiffness of various components as well as the connection stiffness. So the connective quality of thrust bearing and foundation is also of importance. In all, the foundation is required to be as rigid as possible. The reinforced foundation contributes to reducing the shear deflection of the pedestal and relieving the rotation of stern hull. Once the foundation is much too flexible, the thrust collar will be misaligned with respect to the bearing gland face, which is seriously harmful to lubrication performance of thrust bearing and results in increased wear and tear of pads. Only these factors are thoroughly implemented; the problem of insufficient axial stiffness in propulsion shafting system will not occur at all.

\section{Longitudinal Vibration Characteristics of Propulsion Shafting}

5.1. Natural Frequencies of Longitudinal Vibration. The parameters associated with the propulsion shafting system are listed in Table 3.

The 1st and 2nd natural frequencies of propulsion shafting longitudinal vibration in terms of shafting rotating speeds are shown by the Campbell diagram in Figure 10. It seems that the natural frequencies vary with the rotational speeds, especially in the range of low rotational speeds. The finding is contrary to the widely-held understanding that the natural frequencies of propulsion shafting longitudinal vibration are independent of shafting rotating speed. The main reason for this incorrect conclusion is neglect of oil film stiffness. Since the oil film is not considered, the previous studies mistook longitudinal vibration of propulsion shafting as longitudinal vibration of rod. If so, the rotor characteristic of propulsion shafting was factitiously ignored. Virtually, this finding is consistent with the result of laboratory measurement on a scaled experiment rig given by Pan et al. [21].

However with an increase of rotational speed, the 1st and 2nd natural frequencies tend to be constant gradually. The variation amplitude and range of natural frequencies are related to the relative magnitude of oil film stiffness and thrust bearing stiffness. At low speeds, the oil film stiffness is less than that of thrust bearing, and then the effect of rotational speeds on natural frequencies is of increased significance. But the changeability of natural frequencies is slight once the oil film stiffness exceeds that of thrust bearing. For the study, the stiffness of oil film at shafting rotating speed $60 \mathrm{rpm}$ reaches the thrust bearing stiffness, and then the 1st and 2nd natural frequencies are almost invariable in the range of subsequent rotational speeds. Generally, it is the case that the more flexible the thrust bearing is, the narrower the influence range of rotational speeds on natural frequencies is available.

The excitation frequencies of propeller fluctuating thrust are tonal at the blade passing frequency. Obviously, the critical speed corresponding to the 2nd natural frequency is above the rotational speed. Thereby the 1st frequency is of particular interest. Besides, the 1st mode is the most superior mode of propulsion shafting, which contributes to vibratory response greatly.

5.2. Effect of Thrust Bearing Stiffness. As far as the longitudinal vibration is concerned, the structural stiffness of thrust bearing is undoubtedly the most important effect factor. Provided that the construction of thrust bearing was reinforced, the natural frequency of propulsion shafting would rise correspondingly. However, there are rapid change region and slow change region with respect to natural frequency of propulsion shafting in the variation range of thrust bearing stiffness, which is essential to decide whether to modify thrust bearing or shafting rotor when propulsion shafting encounters severe longitudinal vibration.

Most often, the submarine sails at low shafting rotating speeds. Taking the rotational speed $100 \mathrm{rpm}$ as an example, the effect of thrust bearing stiffness on the 1st natural frequency of propulsion shafting longitudinal vibration is given in Figure 11. It appears that the slope of curve decreases gradually with the increase of thrust bearing stiffness. By setting a stiffness increment of $0.5 \times 10^{9} \mathrm{~N} / \mathrm{m}$, only in the range of thrust bearing stiffness $(1 \sim 2.5) \times 10^{9} \mathrm{~N} / \mathrm{m}$ the increase rate of the 1st natural frequency is above $1 \%$. Taking the constant $2.5 \times 10^{9} \mathrm{~N} / \mathrm{m}$ as critical value, the change region is divided into rapid region and slow region, as shown in Figure 11. The measure of altering natural frequency by reinforcing structural configuration of thrust bearing is effective if the initial rigidity of propulsion shafting system is insufficient. Nonetheless, in case that the spring constant of thrust bearing was higher than the critical value, then the scheme of keeping on stiffening thrust bearing to transfer the 1st natural frequency away from the propeller excitation frequency did not work at all.

In the case of as-built submarine, the mounted thrust bearing will be operational forever unless there are failures. It means that the stiffness of thrust bearing unit is established throughout the period of validity, while only the foundation stiffness is changeable. Thus, the variation of thrust bearing stiffness depends on structural modifications of foundation. If the foundation was too flexible initially, especially when the spring constants of foundation and shafting were of the same order of magnitude, a large improvement in stiffening of the foundation would lead to an increase of the 1st natural frequency. Figure 12 shows the effect of considerable variations in foundation stiffness on the 1st natural frequency. The results validate the conclusion. 


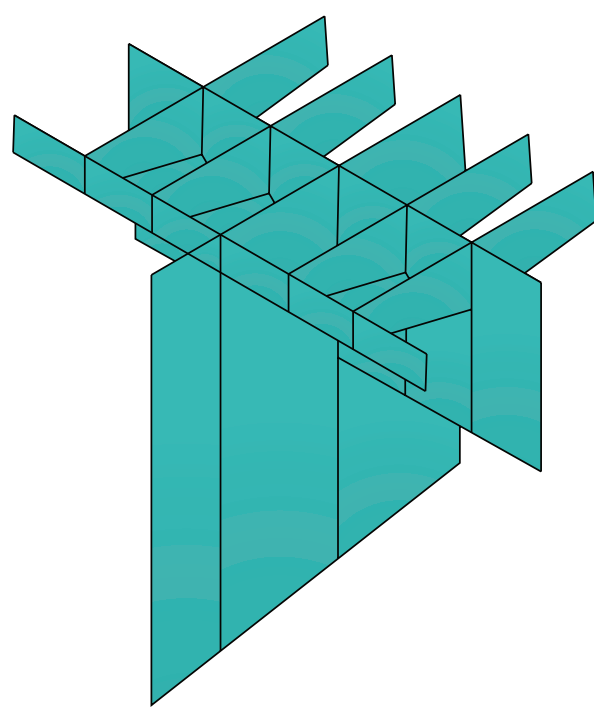

(a) The original

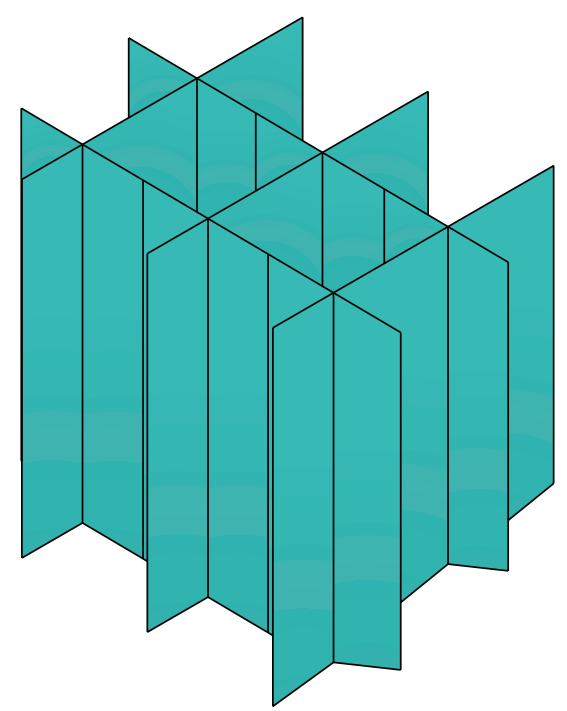

(b) The modified

FIGURE 9: Illustrations of the original and modified internal structural configuration of pedestal.

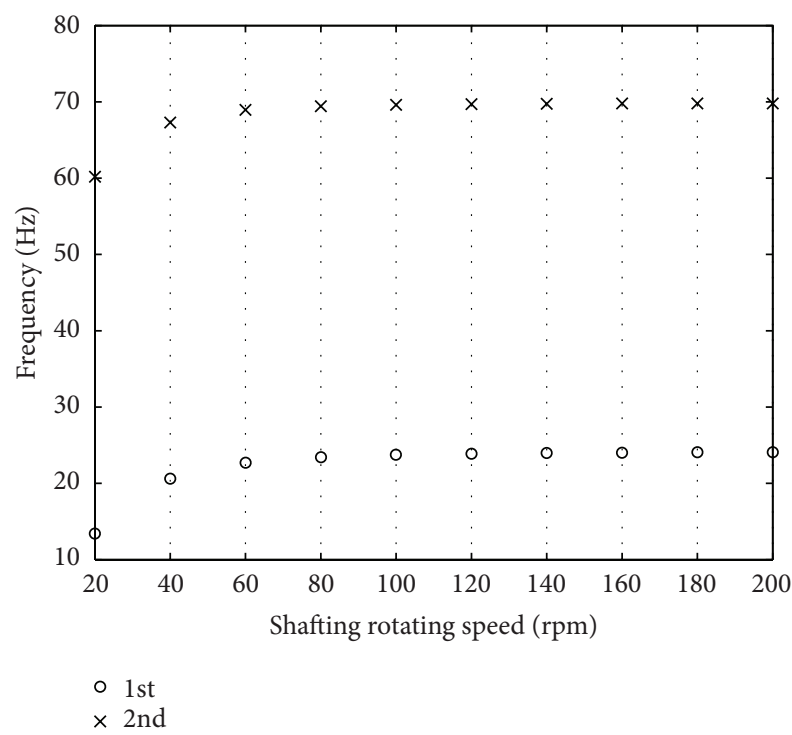

Figure 10: Campbell diagram.

Although the 1st natural frequency varies with spring constant of thrust bearing, the variation amplitude is really limited. Even though the thrust bearing stiffness is multiplied 7 times, the 1st natural frequency only adds $2.5 \mathrm{~Hz}$, let alone how to achieve such large improvement of thrust bearing stiffness in practice. However, the study is very useful for estimation of the 1st natural frequency in new design period of propulsion shafting system. In the preliminary design stage, there is no necessity to determine the thrust bearing stiffness, particularly the foundation stiffness, with a high degree of accuracy. Furthermore, the stiffer the foundation is relative to shafting, the less effect an error in estimating foundation stiffness will have on the 1st natural frequency. For example, if the estimated stiffness of foundation was

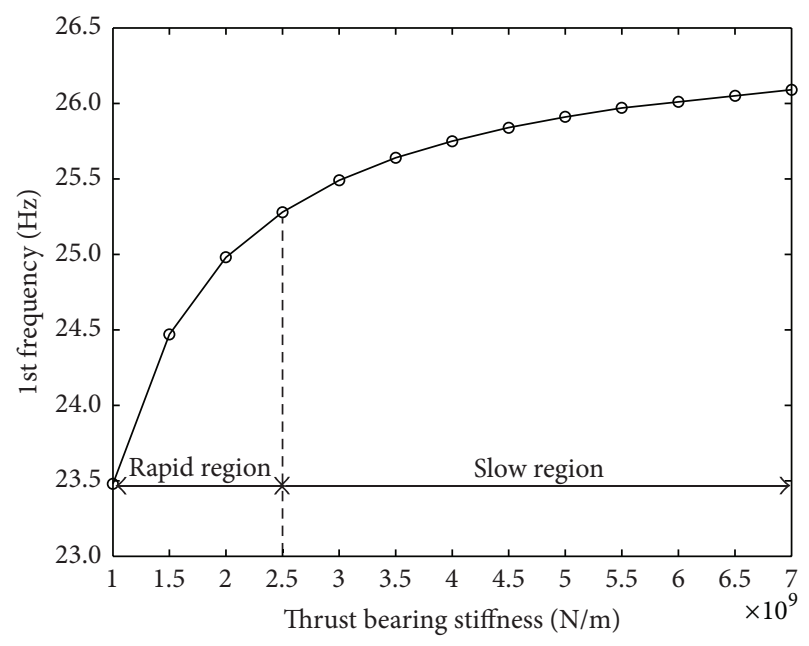

FIGURE 11: Effect of thrust bearing stiffness on the 1st natural frequency.

$1.2 \times 10^{9} \mathrm{~N} / \mathrm{m}$, while the actual value was $1 \times 10^{9} \mathrm{~N} / \mathrm{m}$, the calculated 1st natural frequency was $23.34 \mathrm{~Hz}$ compared with the exact value of $22.88 \mathrm{~Hz}$. Although the error of foundation stiffness reaches up to $20 \%$, the error of the 1st natural frequency is less than $2 \%$.

From the viewpoint of vibration control, the measure of altering natural frequency is one of the simplest control technologies, which can be easily achieved by changes in stiffness and mass. For longitudinal vibration existing in service, the steady response of thrust bearing induced by thrust load at blade passing frequency with respect to various spring constants of thrust bearing is depicted in Figure 13. In calculation, the thrust variation which occurs at the propeller is set as a constant fraction $5 \%$ of the steady thrust at any shafting rotating speed. The hysteretic damping 


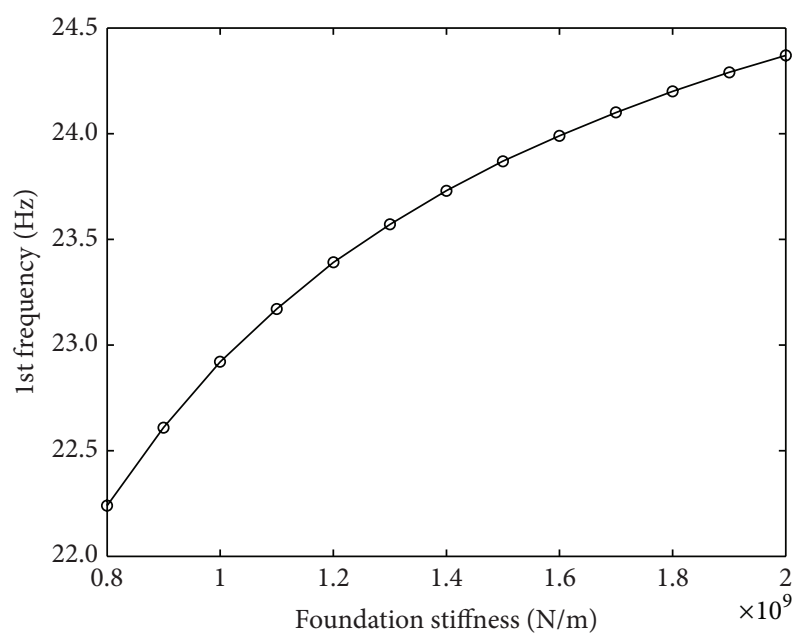

FIGURE 12: Effect of foundation stiffness on the 1st natural frequency.

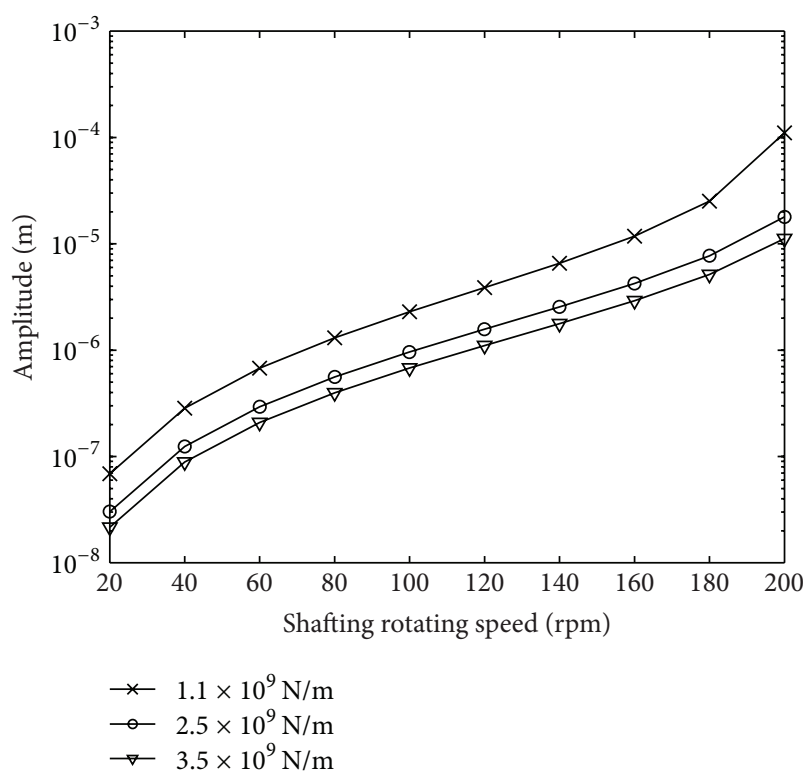

FIGURE 13: Steady response of thrust bearing induced by thrust load at blade passing frequency.

of shafting and structural damping of thrust bearing are included with hysteretic damping ratio 0.02 and loss factor 0.04 , respectively. On one hand, the level of longitudinal vibration is significantly suppressed when the thrust bearing stiffness is largely increased. On the other hand, the attenuation amplitude is not the same in different change region of thrust bearing stiffness. Below the critical value $2.5 \times$ $10^{9} \mathrm{~N} / \mathrm{m}$, the attenuation amplitude is prominent, whereas the attenuation amplitude is slight. However, the effort of achieving reinforced structural configuration of thrust bearing to reduce off-resonance response of longitudinal vibration in propulsion shafting system is proved to be rewarding.

\section{Thrust Transmission through Propulsion Shafting System}

The longitudinal vibration transmission through the propulsion shafting system results in axial excitation of hull and generation of structure-borne noise, which constitutes important source of low-frequency acoustic signature. This type of vibration transmission is actually the propagation of stress wave. The lubricant oil film between thrust collar and tilting pads within thrust bearing serves as the key transmitter of propeller steady thrust from propeller to hull. But unfortunately, the oscillations in thrust are also passively transmitted through the oil film to thrust bearing and hull.

Concentrating at the blade passing frequency and considering the existing understanding of square functional relationship between propeller steady thrust and shafting rotating speed, the fluctuating thrust is still set as a fixed proportion $5 \%$ of steady thrust at different rotational speeds. The propeller fluctuating thrust and dynamic force of oil film in terms of shafting rotating speeds are shown in Figure 14, as well as the thrust load transmitted to hull. It is interesting to find that not only the dynamic force of oil film and thrust load transmitted to hull do not follow the square relationship with the shafting rotating speed as the fluctuating thrust does, but also the amplitudes are magnified. This special phenomenon is the result of the existence of nonlinear characteristics in propulsion shafting system, which is almost contributed by oil film within thrust bearing. Due to the variation of dynamic characteristics of oil film with shafting rotating speed, there is no linear relationship between propeller excitation and shafting response. The nonlinear characteristics enable the propulsion shafting to have the force magnification effect. The results well explain why the longitudinal vibration of propulsion shafting is so harmful to acoustic stealth of submarine.

Further, the thrust transmission characteristics in propulsion shafting system can be described by the force transmissibility in frequency domain. The waterfall plot of force transmissibility versus frequency at different shafting rotating speeds is presented in Figure 15. The low-frequency range up to $100 \mathrm{~Hz}$ using a frequency increment of $0.01 \mathrm{~Hz}$ has been considered. The peaks are attributed to the propeller-shafting resonance. It is observed that the thrust load transmitted to hull is multiplied several times in low-frequency band whether the propulsion shafting is in the resonance state or not. Then, the magnification of thrust load at the blade passing frequency is easy to understand. In comparison, the largest peak at high rotational speed is larger. The immediate reason is that the dynamic coefficients of oil film are greater at high rotational speed correspondingly. If it was likely to decrease the dynamic coefficients of oil film actively by additional control technology, then the transmission of fluctuating thrust through the oil film could be reduced to some extent. This provides new promise in minimization of propeller fluctuating thrust transmitted to hull and subsequent hull vibration.

Figure 16 shows the force transmissibility for the cases of various thrust bearing stiffness at shafting rotating speed $100 \mathrm{rpm}$. It appears that the increase of thrust bearing stiffness 


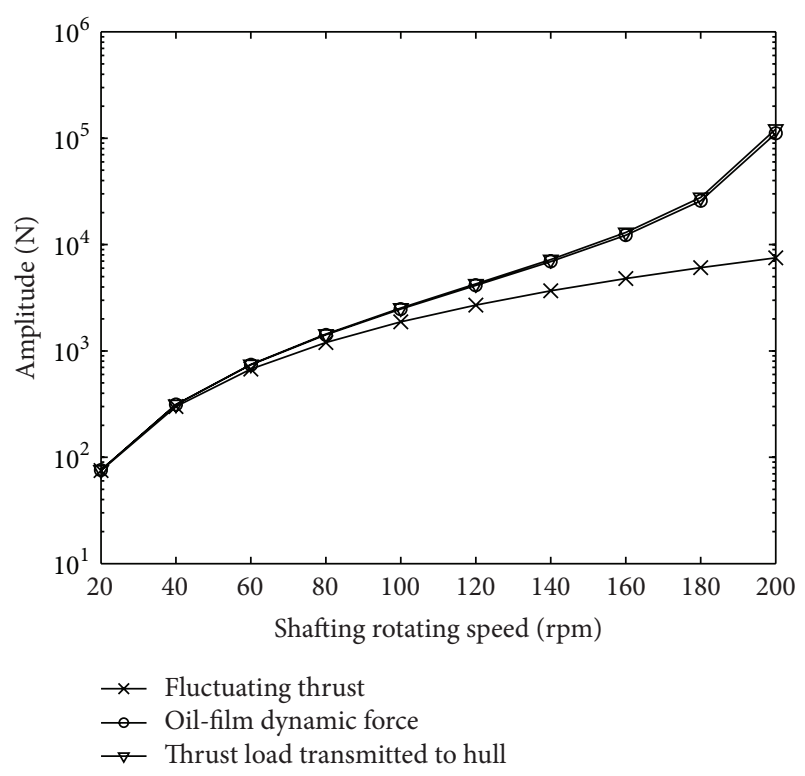

FIGURE 14: Dynamic force acting on propeller, oil film, and hull.

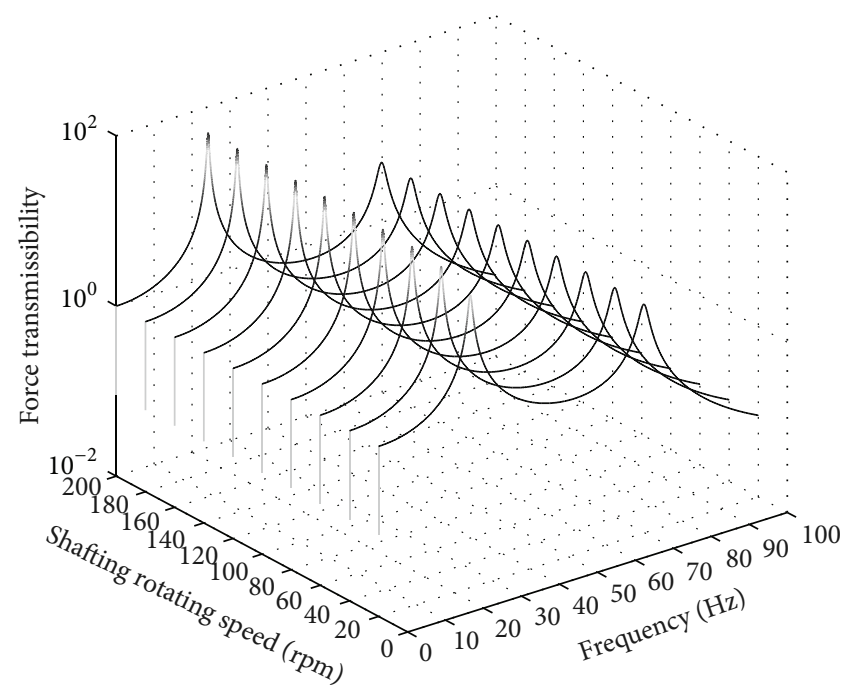

FIGURE 15: Waterfall plot of force transmissibility.

has greater effect to alter the 2nd natural frequency than the 1st natural frequency relatively, and the span of two natural frequencies is expanded. But most importantly, the largest peak is not attenuated effectively. Since the most significant frequency band of propeller excitation is $5 \sim 40 \mathrm{~Hz}$, the measure of stiffening thrust bearing to minimize thrust load transmitted to hull is found to be of little benefit, although it contributes to reduce vibratory response.

\section{Discussion of Thrust Bearing Location}

Although in most of cases stiffening thrust bearing foundation is helpful to alter natural frequency and reduce vibratory response on straight course, it is not always realistic except for drastic changes in structural configuration. Otherwise,

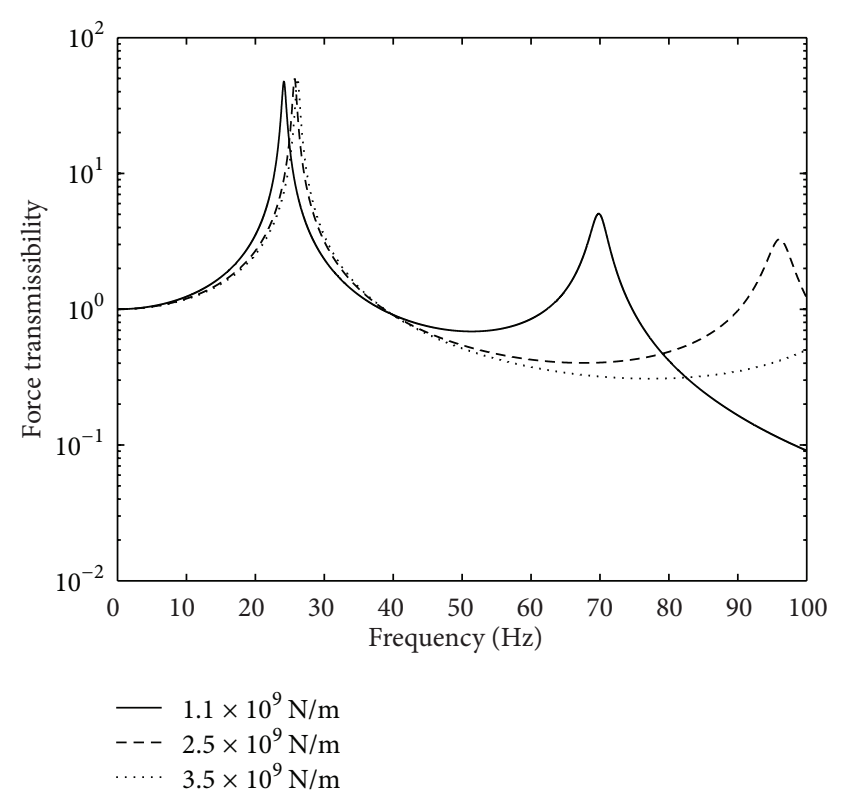

FIGURE 16: Effect of variations in thrust bearing stiffness on force transmissibility.

TABLE 4: Resultant Stiffness of shafting between thrust bearing and propeller.

\begin{tabular}{lccccc}
\hline Displacement $(\mathrm{m})$ & 0 & 0.5 & 1.0 & 1.5 & 2.0 \\
\hline Stiffness $\left(\times 10^{8} \mathrm{~N} / \mathrm{m}\right)$ & 2.24 & 2.37 & 2.51 & 2.68 & 2.86 \\
\hline
\end{tabular}

the stiffness of reinforced thrust bearing steel structure is slightly larger than that of the original. Alternatively, the change of thrust bearing location is more technically feasible in practice.

In view of space and arrangement of the stern, the thrust bearing is only suitable to move backward to the side of propeller, and the range of movement is limited. Since the stern shaft is placed between pressure hull and nonpressure hull, it is not possible to mount thrust bearing there. Hence, the range of thrust bearing movement is confined in the length of the intermediate shaft, as shown in Figure 17. When the thrust bearing is moved backward, the axial rigidity of shafting between thrust bearing and propeller will be enhanced. The axial stiffness of this part of shafting is listed in Table 4.

Also, the case of shafting rotating speed $100 \mathrm{rpm}$ is examined. The influence of moving thrust bearing backward by various displacements on the natural frequency and mode shape of propulsion shafting longitudinal vibration are given in Figures 18 and 19, respectively. The prominent effect is to decrease the span of the two natural frequencies, while the 1st natural frequency is raised largely and the 2nd natural frequency is dropped slightly. Take the example of sevenbladed skewed propeller; once the 1st natural frequency increases by $1 \mathrm{~Hz}$, the critical speed of blade passing frequency will increase by $8.6 \mathrm{rpm}$ correspondingly. When the thrust bearing was located backward by $1 \mathrm{~m}$ relative to the present location, it appears that the critical speed would increase by 


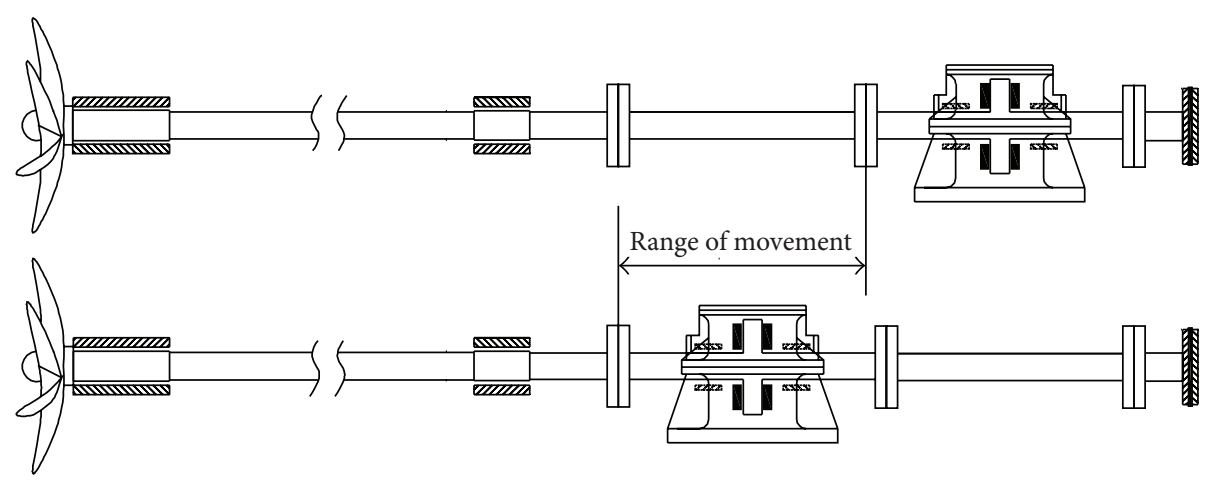

FIGURE 17: The range of thrust bearing movement.

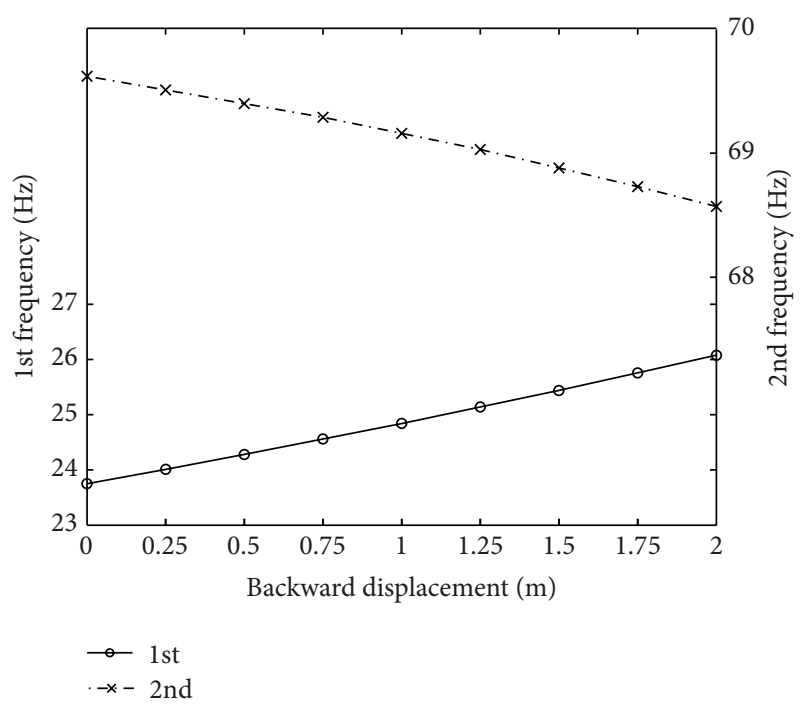

FIGURE 18: Natural frequencies versus backward displacement of thrust bearing.

nearly $10 \mathrm{rpm}$. Besides, it has an effect to decrease amplitude of the 1st mode shape. To display the axial mode shape clearly, it is plotted with the vertical coordinate in Figure 19. The amplitude of mode shape in the whole length of shafting is almost reduced and the degree of amplitude attenuation increases gradually along the length. Compared with the longitudinal wavelength, the shafting is relatively short. That is why the amplitude of the 1st mode shape varies slightly with the shafting length.

From the standpoint of vibration mode, the decrease of mode shape amplitude means the reduction of vibratory response. Under the condition of the same thrust bearing stiffness, the calculated steady response of propeller in time domain is shown in Figure 20. It indicates that the forced response is effectively attenuated when the thrust bearing is mounted backward. Besides, the more distant the movement of thrust bearing is, the better the attenuation effect is. To some extent, it is reasonable to move the thrust bearing backward as much as possible. Viewed from the perspective of the same control effect, the two measures of locating thrust

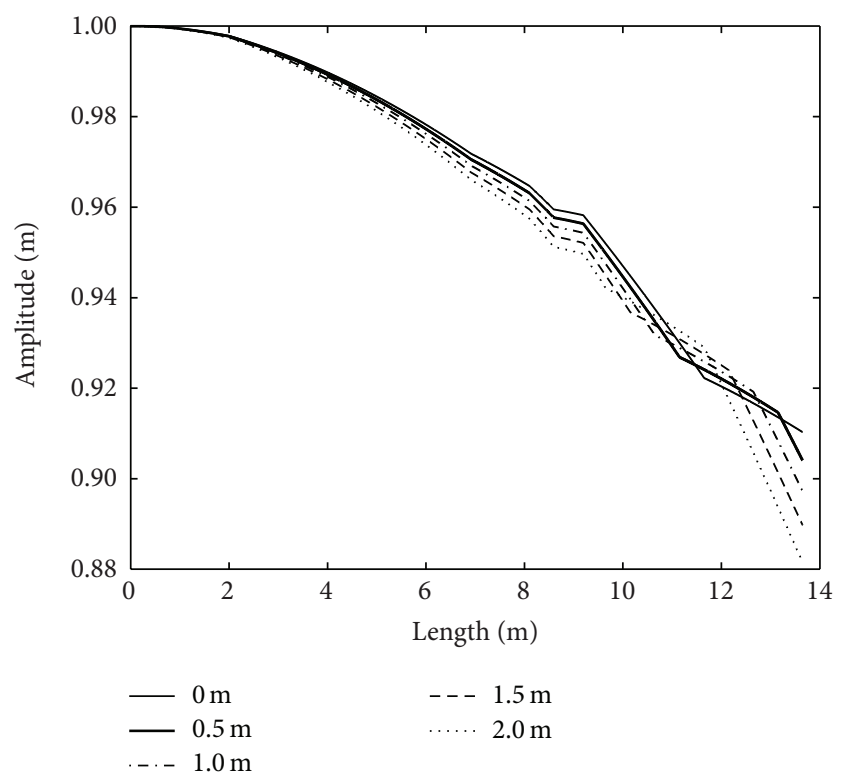

FIGURE 19: 1st mode shape of longitudinal vibration versus backward displacement of thrust bearing.

bearing backward and reinforcing structural configuration of thrust bearing are equivalent. But the former really does work with less cost relatively. Certainly, the attenuation effect will be maximized with the use of these two measures together.

Of particular concern is the effect of minimizing thrust load transmitted to hull with the conjunction of the two measures. Figure 21 presents the effect of variations in thrust bearing stiffness and thrust bearing location on force transmissibility. It is observed that the effect of altering the 1st natural frequency is more prominent as a result of the two measures, but the amplitude of the peaks almost remains the same. The study proves once again that the measures of structural modification have no effect to reduce the fluctuating thrust transmission in the propeller-shafting system. With the intent to minimize the thrust load transmitted to hull, other control technologies must be developed. 


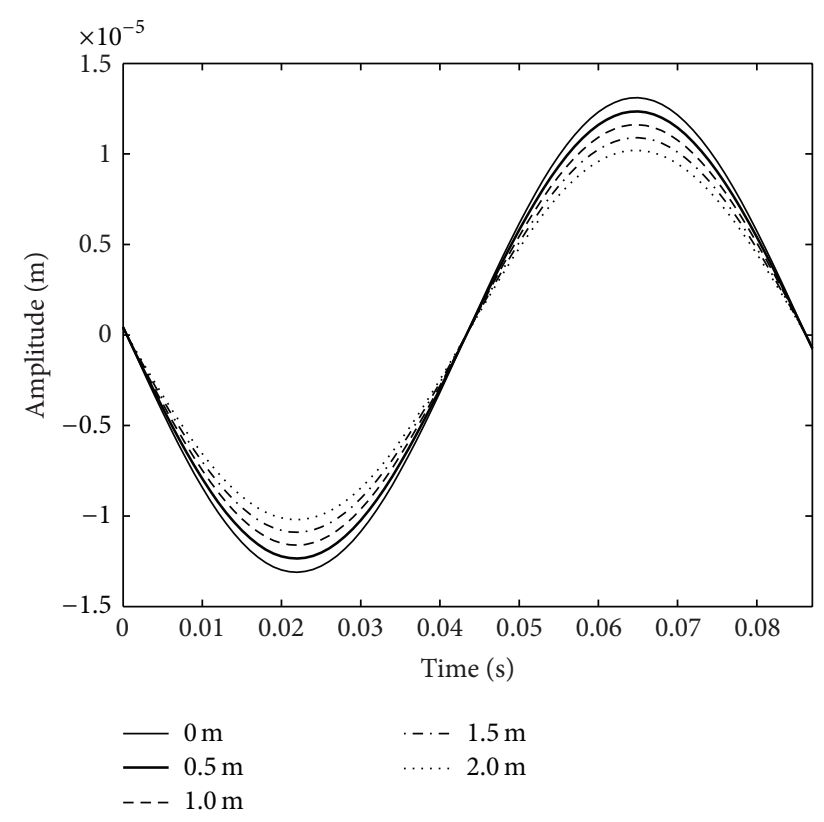

FIGURE 20: Propeller steady response versus various backward displacements of thrust bearing at $100 \mathrm{rpm}$.

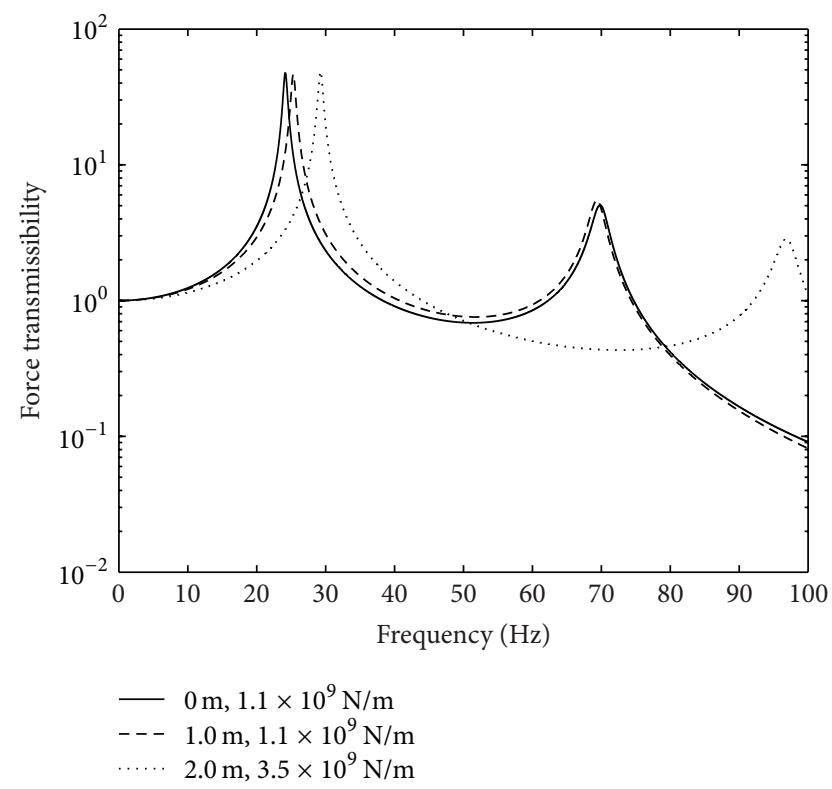

FIGURE 21: Effect of variations in thrust bearing stiffness and thrust bearing location on force transmissibility.

\section{Conclusions}

The study focuses on the problem of longitudinal vibration in submarine propulsion shafting system and belongs to the scope of rotor dynamics. In view of the chain characteristic of propulsion shafting system, the modular transfer matrix model had been established. Firstly, the propulsion shafting system was divided into several subsystems, of which dynamic characteristics are all described by transfer matrixes. To improve accuracy, the transfer matrix of individual subsystem was transformed to the dimensionless form. Then, the calculation methods of stiffness and damping of oil film and foundation stiffness were proposed. Using these obtained values of dynamic parameters, the characteristics of longitudinal vibration and thrust transmission in the propulsion shafting system were analyzed. In the end, the effect of thrust bearing location was discussed.

On the basis of the studies carried out, the following conclusions can be made.

(1) As far as longitudinal vibration is concerned, the axial dynamic characteristics of lubricant oil film between thrust collar and tilting pads within thrust bearing should be included in mechanic model of propulsion shafting system. Combined with the hydrodynamic lubrication theory, the stiffness and damping coefficients of oil film can be solved by the small perturbation method. The thermal effect of lubricant oil affects the solutions significantly and should be taken into account for dynamic analysis of oil film. The oil film stiffness and damping keep pace with the increase of shafting rotating speed nonlinearly.

(2) For as-built submarine, the foundation is the dominant factor of deciding whether the propulsion shafting system is rigid or flexible in axial direction. The FEM is capable of providing sufficient accurate estimation of the foundation axial stiffness. The pedestal makes great contribution to foundation stiffness, while the effect of hull is slight. To achieve reinforced foundation, the effort should be directed toward modifying the internal structural configuration of pedestal. One reinforced scheme is proposed, but the optimized design involving the maximum rigidity and the minimum mass addition still needs to be conducted.

(3) The natural frequencies of propulsion shafting longitudinal vibration vary with the shafting rotating speeds, but the variation amplitude decreases gradually. The fact that the critical speed of the 1st natural frequency falls within the running range needs to attract enough attention. Although the 1st natural frequency can be altered by changes in thrust bearing stiffness, the actual effect of this measure depends on the initial spring constant of thrust bearing. Generally, the critical value $2.5 \times 10^{9} \mathrm{~N} / \mathrm{m}$ is proper to serve as reference. In any case, a large improvement in stiffening of thrust bearing structure contributes to reduce off-resonance response of propulsion shafting longitudinal vibration to some extent.

(4) The thrust load transmitted to hull is multiplied several times in low-frequency band whether the propulsion shafting is in the resonance state or not. The nonlinear characteristics of oil film enable the propulsion shafting to have the force magnification effect. The measure of stiffening thrust bearing is of little benefit to minimize the transmission of propeller fluctuating thrust from the propulsion shafting system to the hull. 


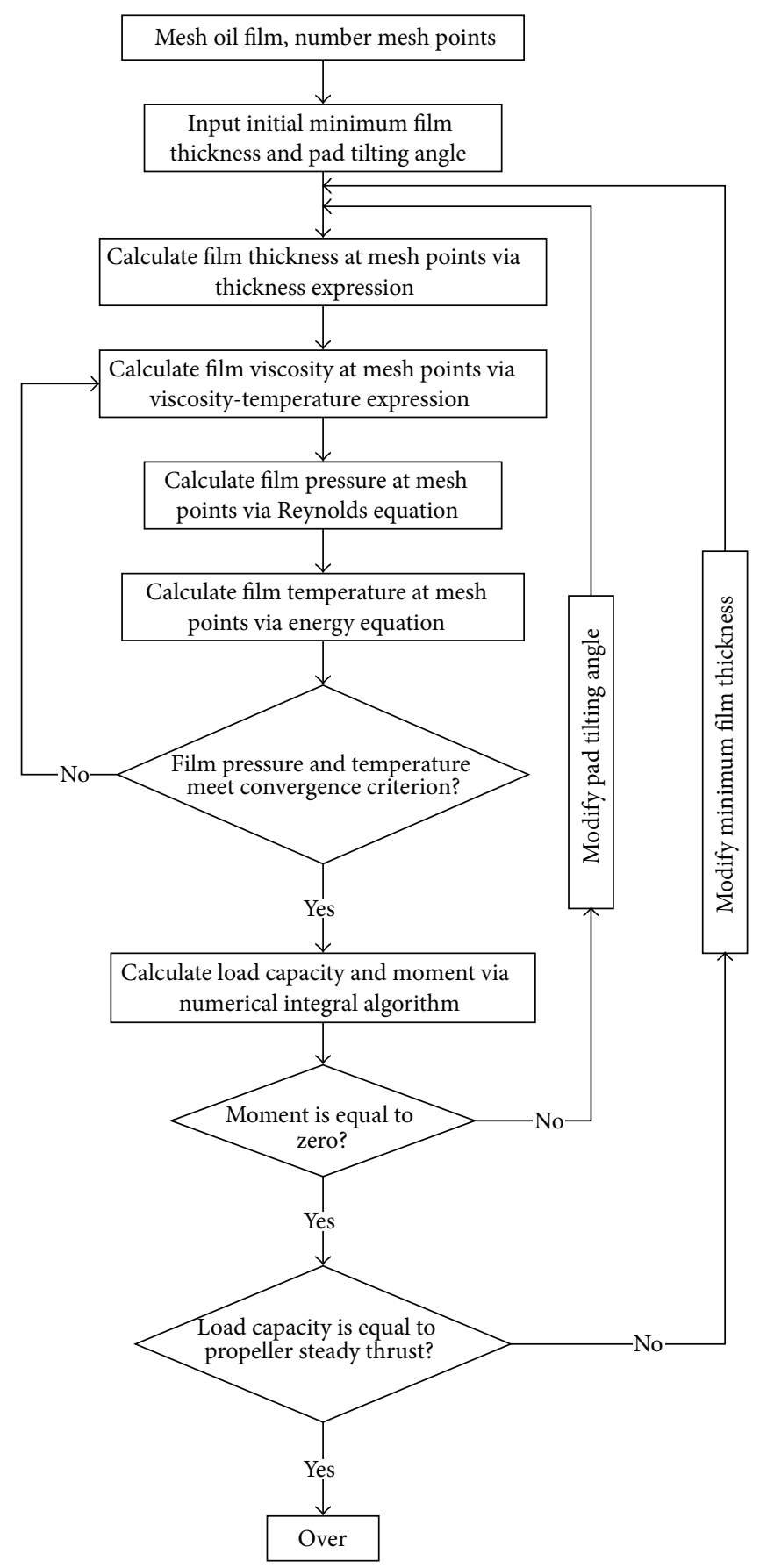

Figure 22: Calculation flow chart of hydrodynamic lubrication.

(5) The benefits of altering the 1st natural frequency and reducing vibratory response validate that the measure of locating thrust bearing backward is effective. Viewed from this perspective, the measure of backward movement of thrust bearing has the same effect as reinforcement of thrust bearing structure. However, the two measures of structural modification fail to minimize thrust load transmitted to hull, and there is necessity to develop other control technologies.

\section{Appendix}

With the central finite difference numerical method, the equations of Reynolds and energy are reduced to finite difference forms as follows:

$$
\begin{gathered}
P_{i, j}=\frac{A_{i, j} P_{i+1, j}+B_{i, j} P_{i-1, j}+C_{i, j} P_{i, j+1}+D_{i, j} P_{i, j-1}-E_{i, j}}{A_{i, j}+B_{i, j}+C_{i, j}+D_{i, j}}, \\
T_{i, j}=\frac{a_{i, j} T_{i-1, j}-b_{i, j} T_{i+1, j}-c_{i, j} T_{i, j+1}+d_{i, j} T_{i, j-1}+e_{i, j}}{a_{i, j}-b_{i, j}-c_{i, j}+d_{i, j}},
\end{gathered}
$$


where the coefficients are

$$
\begin{aligned}
A_{i, j}= & \left(\frac{H^{3}}{U}\right)_{i+(1 / 2), j}, B_{i, j}=\left(\frac{H^{3}}{U}\right)_{i-(1 / 2), j}, \\
C_{i, j}= & R_{i, j}\left(\frac{\Delta \theta}{\Delta R}\right)^{2}\left(\frac{R H^{3}}{U}\right)_{i, j+(1 / 2)}, \\
D_{i, j}= & R_{i, j}\left(\frac{\Delta \theta}{\Delta R}\right)^{2}\left(\frac{R H^{3}}{U}\right)_{i, j-(1 / 2)}, \\
E_{i, j}= & 6 R_{i, j}^{2} \Delta \theta\left(H_{i+(1 / 2), j}-H_{i-(1 / 2), j}\right), \\
a_{i, j}= & \frac{1}{2 \Delta \theta}\left[\left(6-\frac{H^{2}}{U R^{2}} \frac{\partial P}{\partial \theta}\right)_{i, j}+\left|\left(6-\frac{H^{2}}{U R^{2}} \frac{\partial P}{\partial \theta}\right)_{i, j}\right|\right], \\
b_{i, j}= & \frac{1}{2 \Delta \theta}\left[\left(6-\frac{H^{2}}{U R^{2}} \frac{\partial P}{\partial \theta}\right)_{i, j}-\left|\left(6-\frac{H^{2}}{U R^{2}} \frac{\partial P}{\partial \theta}\right)_{i, j}\right|\right], \\
c_{i, j}= & \frac{1}{2 \Delta R}\left[\left(\frac{H^{2}}{U} \frac{\partial P}{\partial R}\right)_{i, j}+\left|\left(\frac{H^{2}}{U} \frac{\partial P}{\partial R}\right)_{i, j}\right|\right], \\
e_{i, j}= & \frac{1}{2 \Delta R}\left[\left(\frac{H^{2}}{U} \frac{\partial P}{\partial R}\right)_{i, j}-\left|\left(\frac{H^{2}}{U} \frac{\partial P}{\partial R}\right)_{i, j}\right|\right],
\end{aligned}
$$

Equation (A.1) are two sets of algebraic equations, in which the pressure at the center point of each mesh is described in terms of pressures, viscosities, and film thickness of the surrounding mesh points and then the temperature at the centers of mesh points are described in terms of the surrounding pressures, viscosities, and film thickness. The two sets of algebraic equations can be effectively solved by two iterative procedures. To accelerate the convergence speed, the overrelaxation iterative algorithm and low-relaxation iterative algorithm are utilized to solve the distribution of pressure and temperature, respectively. The iterative equations are listed as follows:

$$
\begin{gathered}
P_{i, j}^{k}=P_{i, j}^{k-1}+\alpha\left(P_{i, j}^{k}-P_{i, j}^{k-1}\right) \quad(1<\alpha<2), \\
T_{i, j}^{k}=T_{i, j}^{k-1}+\beta\left(T_{i, j}^{k}-T_{i, j}^{k-1}\right) \quad(0<\beta<1) .
\end{gathered}
$$

The definitions of convergence criteria are given by

$$
\begin{gathered}
\frac{\sum_{j=2}^{m} \sum_{i=2}^{n}\left|P_{i, j}^{k}-P_{i, j}^{k-1}\right|}{\sum_{j=2}^{m} \sum_{i=2}^{n}\left|P_{i, j}^{k}\right|} \leq 10^{-3}, \\
\frac{\sum_{j=2}^{m} \sum_{i=2}^{n}\left|T_{i, j}^{k}-T_{i, j}^{k-1}\right|}{\sum_{j=2}^{m} \sum_{i=2}^{n}\left|T_{i, j}^{k}\right|} \leq 10^{-4} .
\end{gathered}
$$

The whole calculation steps can be described with the following flow chart as shown in Figure 22. The program includes the internal and external circulations, which correspond to the iterative computation of tilting angle and minimum film thickness, respectively.

\section{Conflict of Interests}

The authors declare that there is no conflict of interests regarding the publication of this paper.

\section{Acknowledgments}

The authors wish to appreciate the financial support from the Admiralty under Grant no. 401130301.

\section{References}

[1] S. Ishida and T. Yokota, "Measurement and calculation of propeller vibratory force," IHI Engineering Review, vol. 14, no. 1, pp. $1-8,1981$.

[2] C. P. Rigby, "Longitudinal vibrations of marine propeller shafting," Transactions of the Institute of Marine Engineers, vol. 60, pp. 67-78, 1948.

[3] G. B. Zhang and Y. Zhao, "Analysis of vibration and acoustic radiation of submarine hull induced by longitudinal vibration of propulsion shafting," Noise and Vibration Control, vol. 32, no. 3, pp. 155-158, 2012.

[4] A. T. Jaques, "Subsonic Pressure Variation Produced by Submarines," Report 744, Naval Ordnance Lab, 1943.

[5] Y. S. Wei and Y. S. Wang, "Unsteady hydrodynamics of blade forces and acoustic response of a model scaled submarine excited by propeller's thrust and side-forces," Journal of Sound and Vibration, vol. 332, pp. 2038-2056, 2013.

[6] Y. Zhao, G. B. Zhang, and L. W. Li, "Review of advances on longitudinal vibration of ship propulsion shafting and its control technology," Shipbuilding of China, vol. 52, no. 4, pp. 259-269, 2011.

[7] G. B. Zhang and Y. Zhao, "Reduced-order modeling method for longitudinal vibration control of propulsion shafting," in Proceedings of the International Conference on Mechanical, Industrial and Manufacturing Engineering, pp. 73-80, Singapore, 2012.

[8] A. J. H. Goodwin, "The design of a resonance changer to overcome excessive axial vibration of propeller shafting," Institute of Marine Engineers Transactions, vol. 72, pp. 37-63, 1960.

[9] D. W. Lewis, P. E. Allaire, and P. W. Thomas, "Active magnetic control of oscillatory axial shaft vibrations in ship shaft transmission systems. Part 1: system natural frequencies and laboratory scale model," Tribology Transactions, vol. 32, no. 2, pp. $170-178,1989$. 
[10] D. W. Lewis, R. R. Humphris, and P. W. Thomas, "Active magnetic control of oscillatory axial shaft vibrations in ship shaft transmission systems. Part 2: control analysis and response of experimental system," Tribology Transactions, vol. 32, no. 2, pp. 179-188, 1989.

[11] A. Baz, J. Gilheany, and P. Steimel, "Active vibration control of propeller shafts," Journal of Sound and Vibration, vol. 136, no. 3, pp. 361-372, 1990.

[12] L. Xiang, S. X. Yang, and C. B. Gan, "Torsional vibration of a shafting system under electrical disturbances," Shock and Vibration, vol. 19, pp. 1-11, 2012.

[13] P. Lu, Y. Zhao, T. Y. Li, and et. al, "Analysis of coupled vibration of propulsion shafting-hull based on mixed finite element model," Shipbuilding of China, vol. 53, no. 3, pp. 151-157, 2012.

[14] L. Murawski, "Axial vibrations of a propulsion system taking into account the couplings and the boundary conditions," Journal of Marine Science and Technology, vol. 9, no. 4, pp. 171-181, 2004.

[15] M. A. Prohl, "A general method for calculating critical speeds of fiexible rotors," Journal of Applied Mechanics, vol. 12, pp. 142$148,1945$.

[16] B. Sternlicht, J. C. Reid, and E. B. Arwas, "Review of propeller shaft thrust bearings," Journal of the American Society for Naval Engineers, vol. 71, no. 2, pp. 277-290, 1959.

[17] H. Schwanecke, "Investigations on the hydrodynamic stiffness and damping of thrust bearings in ships," Transactions of the Institute of Marine Engineers, vol. 91, pp. 68-77, 1979.

[18] L. Vassilopoulos, "Methods for computing stiffness and damping properties of main propulsion thrust bearing," International Shipbuilding Progress, vol. 29, no. 329, pp. 13-31, 1982.

[19] L. Vassilopoulos and F. M. Hamilton, "Longitudinal stiffness analysis for the propulsion shafting systems of the Polar class icebreakers," Naval Engineers Journal, vol. 92, no. 2, pp. 179-195, 1980.

[20] I. Iordanoff, P. Stefan, R. Boudet, and D. Poirier, "Dynamic analysis of a thrust bearing: effect of misalignment and load," Proceedings of the Institution of Mechanical Engineers J: Journal of Engineering Tribology, vol. 209, no. 3, pp. 189-194, 1995.

[21] J. Pan, N. Farag, T. Lin, and R. Juniper, "Propeller induced structural vibration through the thrust bearing," in Innovation in Acoustics and Vibration, pp. 390-399, Adelaide, Australia, 2002.

[22] P. G. Dylejko and N. J. Kessissoglou, "Minimization of the vibration transmission through the propeller-shafting system in a submarine," Journal of the Acoustical Society of America, vol. 116, no. 4, pp. 2569-2569, 2004.

[23] P. G. Dylejko, N. J. Kessissoglou, Y. Tso, and C. J. Norwood, "Optimisation of a resonance changer to minimise the vibration transmission in marine vessels," Journal of Sound and Vibration, vol. 300, no. 1-2, pp. 101-116, 2007.

[24] G. W. Stachowiak and A. W. Batchelor, Engineering Tribology, Elservier; Butterworth-Heinemann, Burlington, Mass, USA, 3rd edition, 2005.

[25] F. Besnier, L. Jian, L. Murawski, and M. Weryk, "Evaluation of main engine and propeller excitations of ship hull and superstructure vibration," International Shipbuilding Progress, vol. 55, no. 1-2, pp. 3-27, 2008. 

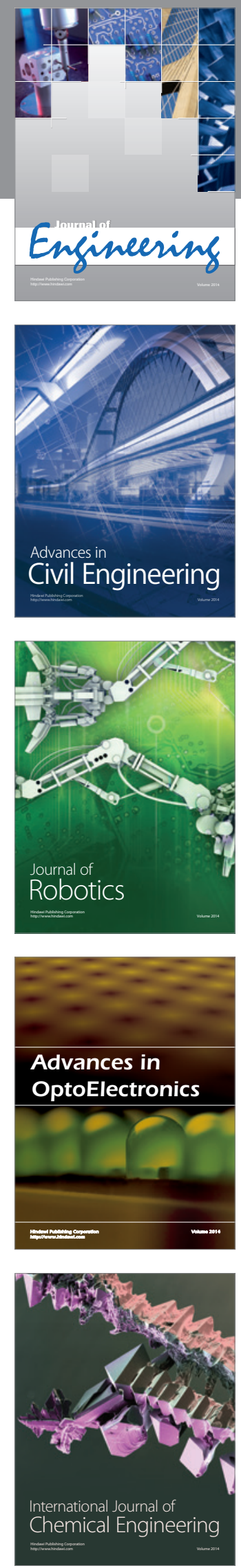

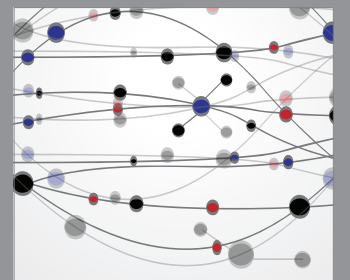

The Scientific World Journal
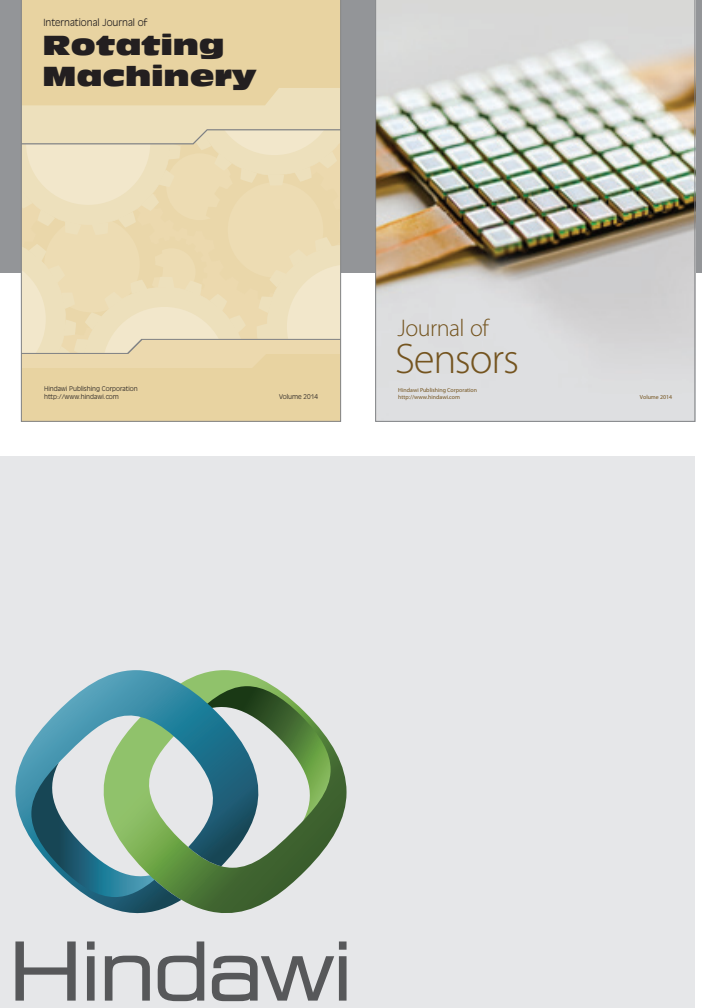

Submit your manuscripts at http://www.hindawi.com
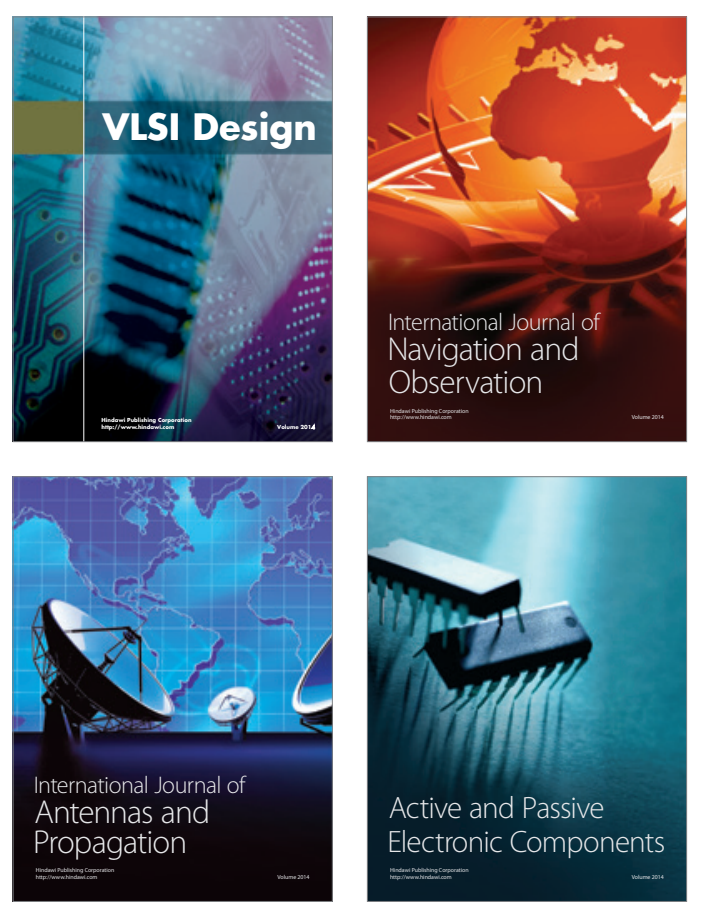
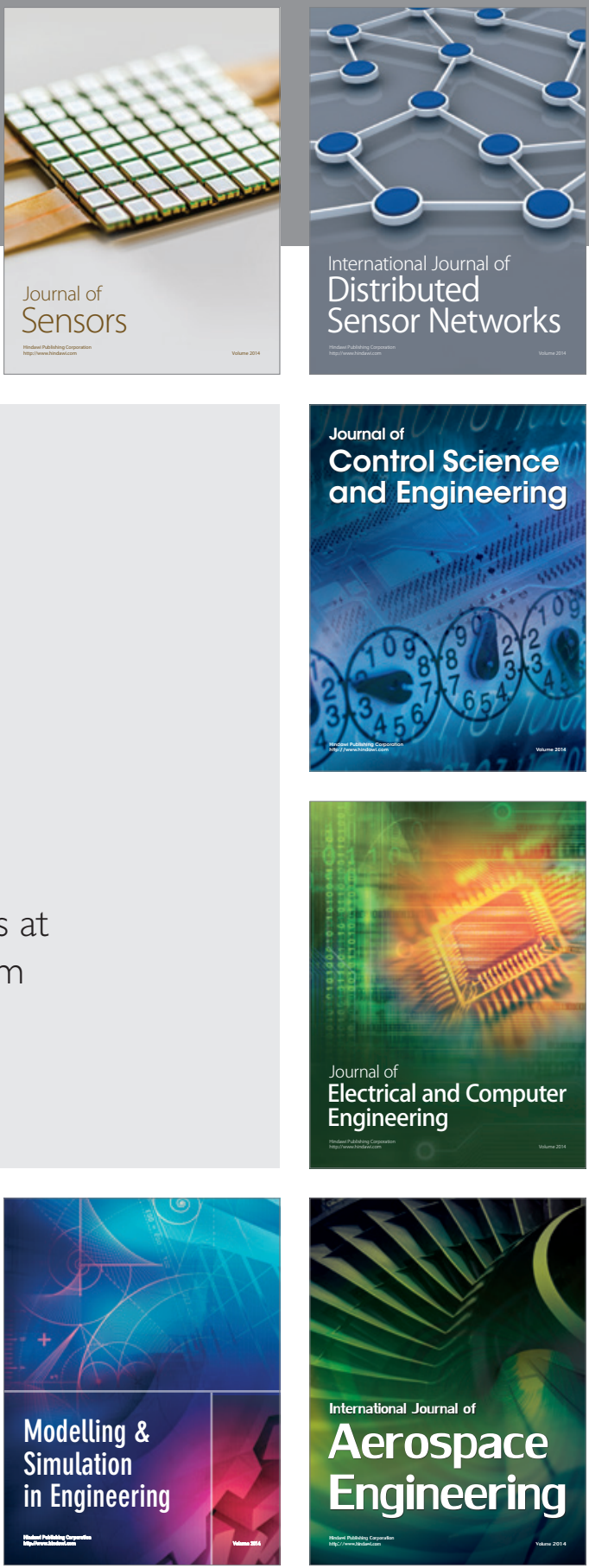

Journal of

Control Science

and Engineering
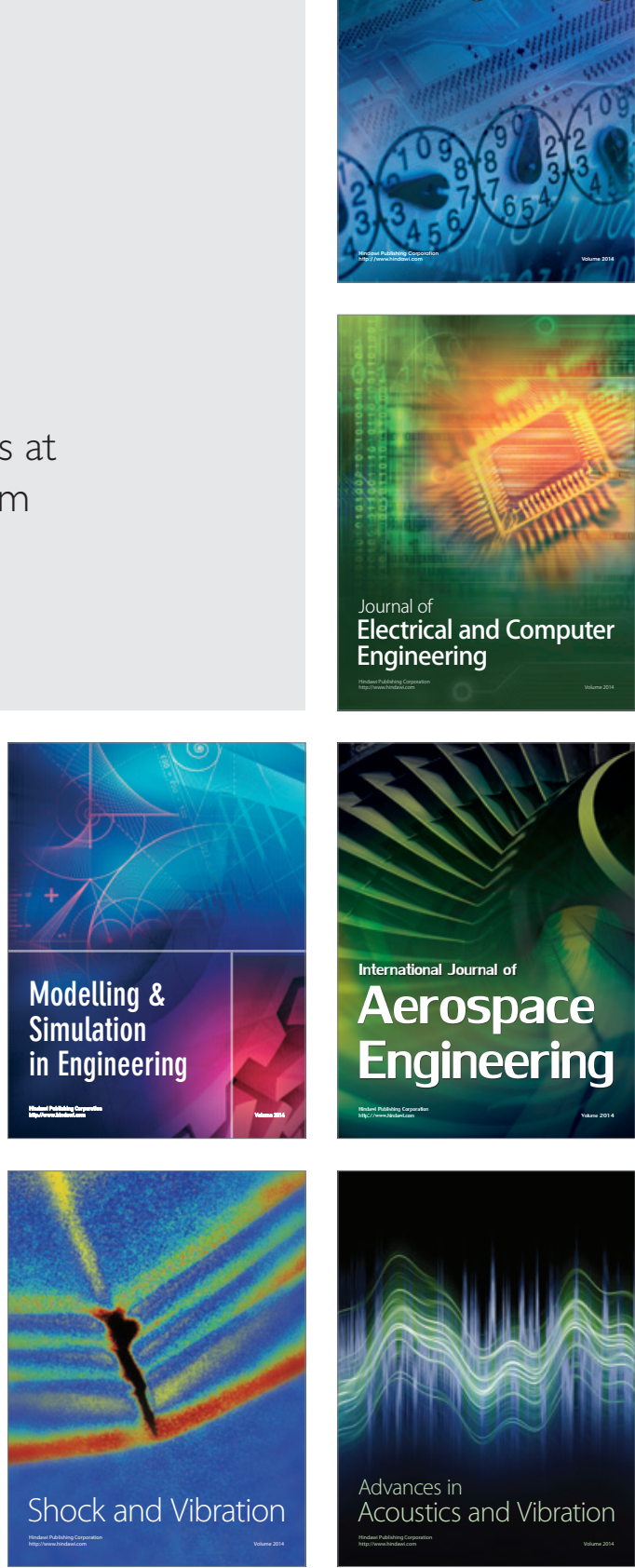